Running head: HELPING TO PROMOTE GENDER EQUALITY

\title{
Loosening the GRIP (Gender Roles Inhibiting Prosociality) to Promote Gender Equality
}

\author{
Alyssa Croft ${ }^{\mathrm{a}}$, Ciara Atkinson ${ }^{\mathrm{a}}$, Gillian Sandstrom ${ }^{\mathrm{b}}$, Lara Aknin $^{\mathrm{c}}$, and Sheina Orbell ${ }^{\mathrm{b}}$ \\ ${ }^{a}$ University of Arizona, ${ }^{b}$ University of Essex, ${ }^{c}$ Simon Fraser University
}

Author Note:

This work was partially funded by a Visiting Fellowship from the British Academy awarded to the first author (VF1\102397). We would like to sincerely thank the Editor and Reviewers who engaged deeply with these ideas and provided extremely thoughtful, constructive suggestions; our paper is immeasurably stronger because of your input. 


\title{
HELPING TO PROMOTE GENDER EQUALITY
}

\begin{abstract}
Prosociality is an ideal context to begin shifting traditional gender role stereotypes and promoting equality. Men and women both help others frequently, but assistance often follows traditional gender role expectations, which further reinforces restrictive gender stereotypes in other domains. We propose an integrative process model of Gender Roles Inhibiting Prosociality (GRIP) to explain why and how this occurs. We argue that prosociality provides a unique entry point for change because it is (a) immediately rewarding (which cultivates positive attitude formation), (b) less likely to threaten the gender status hierarchy, and therefore less susceptible to social backlash (which translates into less restrictive social norms), and (c) a skill that that can be learned (which leads to stronger beliefs in one's own ability to help). Using the GRIP model, we derive a series of hypothesized interventions to interrupt the self-reinforcing cycle of gender role stereotyping and facilitate progress toward broader gender equality.
\end{abstract}

Word count: 150

Keywords: gender roles, gender stereotypes, gender equality, prosocial behavior, helping 


\section{HELPING TO PROMOTE GENDER EQUALITY}

\section{Loosening the GRIP (Gender Roles Inhibiting Prosociality) to Promote Gender Equality}

Equal representation of people with diverse characteristics in various social domains (e.g., occupational, domestic, and leadership roles) is important. Not only should members of underrepresented groups occupy positions of power to ensure equal opportunity and to minimize discrimination, but, due to their increased compassionate and egalitarian orientations, the inclusion of women and minorities in political and corporate leadership roles can positively benefit the welfare of their colleagues and the broader community (Eagly, 2016; Byron \& Post, 2016). Diversification of social roles can also lead to broader shifts in society by dismantling the cultural stereotypes, social norms, and role expectations that limit the number of people who receive particular opportunities (Eagly, 1987; Eagly \& Steffen, 1984; Eagly \& Wood, 2012; Eagly, Wood, \& Diekman, 2000). We argue that one under-utilized strategy for promoting gender diversity and equality is encouraging people to enact prosocial behaviors that run counter to traditional gender role stereotypes. In this paper, we argue that prosociality is a promising entry point for effecting change because helping others is widely valued (for both men and women) and is less likely than other approaches to threaten the existing gender hierarchy. Further, we suggest that shifting gender role stereotypes in the context of prosociality could cause a ripple effect that ultimately undermines broader cultural beliefs about gender roles in other contexts.

Cultural gender role stereotypes shape norms and expectations of what men and women should or should not do, and restrict people's behavior, motivations, self-views, and aspirations (e.g., Croft, Schmader, \& Block, 2015; Diekman \& Eagly, 2000; Diekman \& Goodfriend, 2006; Eagly \& Karau, 2002; Eagly \& Steffen, 1984; Prentice \& Carranza, 2002). As a result, gender stereotypes limit women's opportunities, status advancement, and earning potential (e.g., Brown 


\section{HELPING TO PROMOTE GENDER EQUALITY}

\& Diekman, 2010; Ceci \& Williams, 2011; Croft, Schmader, \& Block, 2019; Park, Smith, \& Correll, 2008; Stout, Dasgupta, Hunsinger, \& McManus, 2011), and restrict men's ability to exhibit communal traits and roles (e.g., Block, Croft, \& Schmader, 2018; Block, Croft, De Souza, \& Schmader, 2019; Croft et al., 2015; Moss-Racusin, 2014). Most efforts to dismantle restrictive and harmful gender stereotypes to promote gender equality have focused on addressing the disadvantages that women face relative to men (e.g., understanding gender equality as a women's issue). These efforts to promote gender equality and increase the representation of women in male-dominated roles were somewhat successful until recently, when progress toward equality has slowed or possibly even stalled (England, Levine, \& Mishel, 2020). Some stereotypes about men and women have shifted over time; men and women are now rated equally competent (Eagly, Nater, Miller, Kaufmann, \& Sczesny, 2020), but women are still judged to be higher in communion, and men are still judged to be higher in agency (Eagly et al., 2020; Haines, Deaux, \& Lofaro, 2016). This decline in the rate of progress toward equality for women is partially due to lingering occupational gender segregation, as well as to the lack of attention previously paid to increasing men's representation in female-dominated roles. In other words, although cultural stereotypes and gender roles governing women's behavior have shifted to enable women to "be more like men," there has not been a similar shift in norms surrounding men's behavior (e.g., Croft et al., 2015; England et al., 2020). Thus, in order to promote gender equality more broadly, efforts to address cultural stereotypes and gender roles should challenge the restrictions placed on women and men alike.

Given the higher status of stereotypically-male (relative to stereotypically-female) roles, traits, and behaviors (e.g., Block et al., 2019; Ridgeway \& Correll, 2004), it makes sense that previous efforts to enhance gender equality have focused on pushing women to "become more 


\section{HELPING TO PROMOTE GENDER EQUALITY}

like men." However, recent research on the asymmetrical rate of change in gender roles (i.e., women's roles changing more quickly than men's roles) considers the other side; this research suggests a host of internal (e.g., internalization of gender stereotypes) and external (e.g., social sanctions from others) barriers prevent men from adopting roles that are predominately occupied by women (see Croft et al., 2015). Underlying many of these internal and external barriers is the enduring status differential between men and women; men, who enjoy a position of privilege and power over women in the gender status hierarchy, are understandably reluctant to relinquish that power in fear of "becoming more like women" (e.g., Croft et al., 2015; Moss-Racusin, 2014; Ridgeway \& Correll, 2004). To achieve gender equality by shifting stereotypes that restrict men, it is crucial to increase the status of stereotypically female roles, traits, and behaviors.

In this paper we argue that addressing gender gaps in prosocial behavior, a communal act that is generally construed as female-stereotypic, could serve as a fruitful first step toward the broader goal of promoting gender equality and reducing the impact of gender role stereotypes across a variety of domains. We reason that people may be more willing to violate gender stereotypes in the domain of prosocial behavior because it is one in which people are less likely to be penalized for violating gender roles; people are less likely to be penalized because helping is cross-culturally valued for men and women, and it is unlikely to threaten the existing gender hierarchy.

We focus specifically on everyday prosocial acts that are relatively simple and commonplace because their prevalence affords familiarity and abundant opportunities for intervention. These behaviors take many forms, such as helping a neighbor with yard work, providing moral support to a friend or colleague, and jumpstarting a car for stranger. Notably, we target deliberate helping behavior for two reasons. First, deliberate decisions tend to be less 


\section{HELPING TO PROMOTE GENDER EQUALITY}

generous and cooperative than automatic decisions (e.g., Rand, 2016; Rand, Greene \& Nowack, 2012; Zaki \& Mitchell, 2013), suggesting that deliberate helping may be in greater need of attention. Second, research shows that conscious reflection can shift everyday helping (e.g., how much, if any, to give to charity; e.g., Stutzer, Goette, \& Zehnder, 2011), and, as discussed later, impact automatic decision and behavior over time. Given that implicit and internalized gender stereotypes can guide behavior outside conscious awareness (e.g., Baron, Schmader, Cvencek, \& Meltzoff, 2014) in ways that are likely to inhibit gender inconsistent helping, we posit that deliberate interventions could alter this behavior.

In addition, we provide an integrative process model (Figure 1), the Gender Roles Inhibiting Prosociality (GRIP) model, to outline the distal (systemic, macro-level) and proximal (individual, micro-level) pathways through which gendered helping (i.e., restricting one's behavior to include only helping acts that are gender-stereotypic; stereotypically masculine helping among men versus stereotypically feminine helping among women) is maintained and perpetuated over time. Furthermore, we propose interventions that could be used to strategically interrupt the proximal pathways at multiple points in the psychological process. The proposed model is largely consistent with dual process theories of social cognition (e.g., Chaiken \& Trope, 1999; Kahneman, 2011). Specifically, cultural gender stereotypes map onto System 1 processes because they become internalized and influence people's attitudes, norms, and efficacy to automatically guide people's decisions about helping, outside their conscious awareness (Ajzen, 2011). However, as with other efforts to curb the impact of implicit biases on decision making and behavior, awareness is key; by recognizing and actively reflecting on the default responses that come on line automatically (thereby engaging System 2 processes), helpers are in a better position to override their habitual, overlearned responses in favor of changing their behavior. 


\section{HELPING TO PROMOTE GENDER EQUALITY}

We begin by reviewing broader theory and research on gender stereotypes, gender-based status differences, and asymmetrically changing gender roles. Next, we narrow our focus toward a more specific discussion of how gender roles inhibit gender-atypical helping at the proximal level through a combination of negative attitudes, perceptions of restrictive social norms, and low self-efficacy beliefs. Finally, we integrate research and theory on multiple topics to derive testable hypotheses for intervening in the process of gendered helping to promote broader gender equality. We argue that people might (a) not realize how much helping others (even in ways that cross gender boundaries) has the potential to boost their mood, (b) overestimate the extent to which they will face social sanctions when they help in ways that cross gender boundaries, and (c) likely do not acknowledge that they have the skills and capabilities to help in myriad ways. By challenging these specific barriers around gendered helping, we are optimistic that repeated helpful acts (and observations of these acts) that transgress traditional gender role stereotypes will begin to soften the rigidity imposed by gender role stereotypes on other social roles as well (e.g., in domestic and workplace domains, leadership, etc.). While we do not expect our theorized interventions to dissolve or reverse gender roles entirely, we argue that they are well positioned to spur incremental movement toward gender equality at a time when progress appears to be stagnating (England et al., 2020).

\section{Contextual Considerations: Gender Roles, Status Differentials, and Communal Behavior}

The purpose of this section is to provide the overarching social context in which genderdifferentiated behavior occurs and reinforces gender stereotypes, as explained by Social Role Theory (Eagly, 1987). After briefly summarizing this theoretical process, we review evidence that gender roles have been changing asymmetrically, and explore how this differential rate of change is moderated by disparities in the perceived status of gendered roles and behaviors. 


\section{HELPING TO PROMOTE GENDER EQUALITY}

Social Role Theory (SRT; Eagly, 1987; Eagly \& Wood, 2012) provides an important account of gender differences in behavior across many domains, including prosocial behavior (e.g., Eagly \& Crowley, 1986; Becker \& Eagly, 2004; Diekman \& Clark, 2015). SRT posits that, due to a combination of biological (e.g., men's larger physical size, women's reproductive abilities) and social factors (e.g., local economy and culture), men and women occupy different social roles within a society. Seeing men and women occupy these different social roles leads to assumptions about the inherent characteristics needed to perform tasks relevant to the social roles, resulting in gender role expectations. For instance, because women are typically seen in communally oriented roles, they are assumed to be more inherently communal. These beliefs about what men and women are like (i.e., stereotypes) guide and influence people through biological, social, and psychological processes (Wood \& Eagly, 2010), resulting in gender differences in behavior. Critically, SRT states that if men and women were to take on new roles, with new demands, gender stereotypes would shift accordingly. Consistent with this idea, stereotypes about women's competence have changed as women's labor force participation and educational attainment has increased (Eagly et al., 2020).

In most Western contexts, however, there has been a systematic asymmetry in the extent to which gender roles have changed over time. Specifically, women's traits and roles have transformed much more rapidly than men's, such that the rigid nature of traditionally masculine stereotypes and expectations have remained relatively stable in recent decades (see Croft et al., 2015 for a review). Indeed, social psychological evidence indicates that men's roles remain more rigid than women's as a result of a host of internal (e.g., self-stereotyping) and external (e.g., social sanctions) factors that limit men's interest in adopting communal roles (Block et al., 2018; Block et al., 2019; Croft et al., 2015). In this section, we discuss a few of these factors in greater 


\section{HELPING TO PROMOTE GENDER EQUALITY}

detail because they provide a backdrop for understanding how promoting gender egalitarian prosocial behavior might also facilitate gender equality in other domains.

One key explanation for the persistent rigidity in men's (relative to women's) roles stems from precarious manhood (Bosson \& Vandello, 2011; Vandello, Bosson, Cohen, Burnaford, \& Weaver, 2008) and concerns about identity misclassification (Bosson, Prewitt-Freilino, \& Taylor, 2005; Bosson, Taylor, \& Prewitt-Freilino, 2006). Past research and theorizing point to masculinity being "hard won and easily lost" (Vandello \& Bosson, 2013). In contrast to womanhood, manhood must be repeatedly proven, verified, and confirmed because there is a perception that manhood can be challenged and stripped away from a man who behaves in a stereotypically feminine way (Bosson \& Vandello, 2011; Vandello et al., 2008). Work on precarious manhood has also shown that when men are asked to engage in a female-stereotypic behavior, they often attempt to reaffirm their masculinity through acts of stereotypic manliness (e.g., acting aggressively; Bosson \& Vandello, 2011), unless they are first given an opportunity to assure others of their heterosexuality (e.g., Bosson et al., 2005).

Importantly, the precariousness of manhood exists within a hierarchical social system in which men's traits, roles, and behavior are typically awarded higher status than women's (e.g., Croft et al., 2015; Ridgeway \& Correll, 2004). Maintaining this existing status hierarchy (i.e., preserving men's relative power over women) is a key motive underlying social backlash effects; violations of traditional gender roles and stereotypes are seen as challenging the status hierarchy, and are therefore punished (Moss-Racusin, Phelan \&, Rudman, 2010; Rudman, Moss-Racusin, Phelan, \& Nauts, 2012). For example, this kind of social policing has been documented in the form of hiring discrimination. In a series of studies, Rudman and colleagues (2012) found that agentic female leaders who displayed dominance, a trait proscribed for women and one that 


\section{HELPING TO PROMOTE GENDER EQUALITY}

challenges the gender hierarchy, were rated as equally competent to agentic men, but were less likely to be hired than agentic men. Other empirical work has revealed that people see men's roles as higher status to such a strong degree that they are less supportive of efforts to promote gender equality in lower status occupations where men are in the minority (i.e., primarily communally-oriented occupations) versus higher status occupations where women are in the minority (i.e., STEM and leadership domains; Block et al., 2019). As such, cultural stereotypes about masculinity and expectations for men's hyper-masculinized behavior contribute to maintaining a systematic pattern of gender inequality. In such a system, women's opportunities for advancement and equality are restricted (directly and indirectly) by the rigidity of men's gender roles (Croft et al., 2015; England et al., 2020).

Efforts to increase gender equality are hindered by men's lack of engagement in communal behaviors. While women are encouraged to adopt more agentic behaviors, they are also expected to maintain primary responsibility for the communal behaviors they traditionally perform, which limits opportunities for advancement. For example, women are often expected to juggle careers alongside personal and societal expectations for childrearing in order to "have it all.” Moreover, working mothers spend disproportionately more time than working fathers doing domestic tasks like childcare and housework, even when working an equivalent number of hours for pay (e.g., Croft, Schmader, Block, \& Baron, 2014; Hochschild \& Machung, 2012; Horowitz 2015; Pew Research Center, 2015). This second shift for working mothers means that they have less time to spend on professional development or attend networking events that could enhance their career and position them for leadership roles. As such, women are also more likely than men to report that their career advancement has been hindered by having to care for children or family members at home (Parkner, 2015). Importantly, these communal domestic and caregiving 


\section{HELPING TO PROMOTE GENDER EQUALITY}

behaviors are typically unpaid and lower in status relative to agentic behaviors like advancing one's career and contributing financially to the family (Block et al., 2018; 2019). This lack of incentives explains why men are unlikely to transgress traditional gender roles in order to contribute in these ways, even if they are willing and interested (see Croft et al., 2015). Prosocial behavior, however, is one type of communal behavior in which men already actively participate, thereby making it an ideal starting place for examining how to shift gender stereotypes in other domains.

\section{Gender Differences in Prosocial Behavior}

As reviewed above, previous research has documented that men and women take on roles that are consistent with agency and communion in various domains, such as work and home. Perhaps not surprisingly, these gender differences extend to prosocial behaviors as well. Men tend to engage in agentic forms of helping behavior, which are more aligned with masculine traits (e.g., risk taking, assertiveness, status seeking). Meanwhile, women tend to engage in more communal forms of helping behavior, which are more aligned with feminine traits (e.g., warmth, other-orientedness, nurturing). The causes of these gender differences in helping can be interpreted through the lens of Social Role Theory (Eagly \& Wood, 2012). In a seminal paper, Eagly and Crowley (1986) conducted a large-scale review of the psychological literature on prosocial behavior, and meta-analyzed the degree to which prosocial behavior is moderated by gender. They concluded that while men and women are both likely to help others, the types of help provided are systematically different, especially in contexts where gender roles are highly salient.

\section{Agentic (Masculine) Forms of Helping}




\section{HELPING TO PROMOTE GENDER EQUALITY}

Consistent with gender stereotypes aligning masculinity with agency and risk-taking, studies show that men are more expected (and more likely) than women to help in high-risk situations, such as providing unsolicited help to strangers and performing heroic acts in emergencies (Becker \& Eagly, 2004; Rankin \& Eagly, 2008). Women are less likely than men to provide help when they perceive helping to be dangerous (Eagly \& Crowley, 1986), and less likely to provide unsolicited (versus requested) help to strangers (Eagly, 2009; Eagly \& Crowley, 1986). Due to their increased physical size and their over-representation in physically demanding occupations, men have an advantage when helping in physically demanding, heroic scenarios such as rescuing people from fires or drowning (Becker \& Eagly, 2004). It is relevant to note that women also engage in heroic and high-risk prosocial behaviors (e.g., living kidney donors, Peace Corps workers, and volunteer Doctors of the World; Becker \& Eagly, 2004). However, the types of heroic helping dominated by men typically demand increased physical strength and involve more rapid decision making, both qualities associated with stereotypical masculinity.

Perhaps one of the most well-known forms of masculine helping is chivalry. Chivalrous helping behaviors are those in which a more powerful, competent group serves to protect and perform polite, courteous acts toward a less powerful group. These chivalrous types of helping behaviors are most likely to occur in contexts where gender roles are salient (Dovidio \& Penner, 2001), such as the early stage of heterosexual dating. Research demonstrates that heterosexual dating scripts rely heavily on traditional gender role expectations (e.g., Eaton \& Rose, 2011; Rose \& Frieze, 1993; Sanchez, Fetterolf, \& Rudman, 2012). Indeed, in an observational study, men were more likely to hold doors for women (vs. women holding doors for men), especially in dating versus everyday contexts (Yoder, Hogue, Newman, Metz, \& LaVigne, 2002). In another 


\section{HELPING TO PROMOTE GENDER EQUALITY}

study, men primed with romantic love were more likely to help a female confederate, but not a male confederate, pick up items they had dropped (Lamy, Fischer-Lokou, \& Guéguen, 2009).

Two additional forms of agentic helping, which are conceptually related to chivalry, are dependency-oriented and instrumental helping. As its name suggests, dependency-oriented help is performed when the helper fixes the problem for the recipient, creating an ongoing dependence upon the helper, rather than empowering the recipient to solve the problem on their own. Research shows that men who are high in benevolent sexism are more likely to provide dependency-oriented help to women rather than autonomy-oriented help (Shnabel, Bar-Anan, Kende, Bereket, \& Lazar, 2016). By helping women in this way, benevolently sexist men reinforce their advantaged position in the gender status hierarchy by ensuring that women continue to rely on them for help (see Kende \& Schnabel, 2017). In a similar vein, provision of instrumental support involves direct problem-solving behaviors (e.g., helping with chores and errands), whereas provision of moral or emotional support involves indirect helping behaviors (e.g., making someone feel valued, loved, and cared for; Morelli, Lee, Arnn, \& Zaki, 2015). Cultural gender stereotypes dictate that men should do this more frequently than women, though empirical evidence is mixed regarding whether this stereotype maps onto actual behavior (e.g., Verhofstadt, Buysse, \& Ickes, 2007; Zhou, Heather, Cesare, \& Ryder, 2017). Nonetheless, both dependency-oriented helping and the provision of instrumental (rather than emotional) support are associated with stereotypical masculinity and agency.

\section{Communal (Feminine) Forms of Helping}

Prosocial behavior aligned with the female gender role is communally-oriented, mainly involving care and concern for others. Within close relationships, women are more likely than men to offer help by providing emotional support (e.g., Burleson \& Kunkel, 2006; Verhofstadt et 


\section{HELPING TO PROMOTE GENDER EQUALITY}

al., 2007; Zhou et al., 2017), and are more likely to provide care to members within their household, including children and elderly relatives (Cancian \& Oilker, 2000). In fact, a review assessing informal care provided to elderly family and friends found that the vast majority (roughly 70\%) of informal caretakers are women (Orbell, 1996). Not only do women provide more emotional support than men, but they are perceived to be more effective providers. Both men and women report preferring to receive emotional support from women (Burleson \& Kunkel, 2006), and women are perceived to be more sensitive and aware of the emotions of others (Cross \& Madson, 1997). Interestingly, gender differences in investment of emotional support and care begin during early childhood, wherein young girls' peer interactions are reported to emphasize more helping, self-disclosure, and empathy than boys' peer interactions (Rose \& Rudolph, 2006).

Women's communally-oriented helping is not limited to their close relationships, but also extends into the workplace. While men and women are both helpful at work, women tend to engage in more altruistic citizenship behaviors than men, such as "going the extra mile" by helping co-workers solve work-related problems and providing social support (Farrell \& Finkelstein; 2007; Heilman \& Chen, 2005; Kidder, 2002). This can also include what is referred to as emotional labor: regulating one's own emotions to fulfill the requirements of a job (e.g., maintaining politeness even when feeling upset by rude customers). Minimizing one's own emotions to avoid inconveniencing others at work is typically underappreciated and invisible, and doing so predicts important outcomes like employee burnout and decreases in well-being (see Grandey \& Gabriel, 2015 for a review). Moreover, in a study examining gender differences in physicians' communication with patients, researchers found that female physicians were more 


\section{HELPING TO PROMOTE GENDER EQUALITY}

likely than male physicians to engage in communally-oriented care, and to use more positive and emotion-focused language (Rotter, Hall, \& Aoki, 2002).

Communally-oriented organizational citizenship behavior can also be seen among women in leadership roles. Managers and leaders have a strong impact on the development of subordinate employees. In a review of gender and leadership styles, Eagly, Johannesen-Schmidt, and van Engen (2003) reported gender differences in male and female managers' interactions with subordinate employees. Specifically, female leaders were more transformational in their leadership, engaging in behaviors that develop and mentor subordinates, as well as attending to their individual needs. Meanwhile, male and female leaders differed in the ways that they were transactional in their leadership, with men engaging in less direct mentorship, only intervening to assist in subordinates' tasks when necessary, and withholding rewards and benefits until employees satisfactorily perform their duties. While it is important to note that the magnitude of these gender differences in leadership style are small, the gender differences that do emerge are in line with the agentic and communal gender role expectations for men and women (Eagly et al., 2003).

In sum, there are prominent cultural stereotypes about differential kinds of helping enacted by men and women. Stereotypes about masculinity and agency suggest that men should enact more heroic, chivalrous, and instrumental kinds of help, whereas stereotypes about femininity and communion suggest that women should enact more relational, nurturing, and emotional kinds of help. These stereotypes manifest in actual gender differences in helping behavior, though perhaps not as strictly as norms might imply (e.g., mixed results with respect to men's engagement in instrumental support). In understanding when, why, and how gender stereotypes impact individual people's decisions about whether or not to help in a given 


\section{HELPING TO PROMOTE GENDER EQUALITY}

situation, we turn to a discussion of the distal (system-level, macro) and proximal (individuallevel, micro) factors that predict gendered helping behavior. Our goal is to synthesize and integrate existing research and theorizing related to the effect of gender stereotypes on behavior to chart a pathway toward gender equality using prosocial behavior as a catalyst. We propose an integrative process model of gender roles inhibiting prosociality to organize these psychological factors into a cogent framework from which hypotheses and testable interventions can be derived (see Figure 1 and Table 1).

\section{An Integrative Process Model of Gender Roles Inhibiting Prosociality (GRIP)}

Our contribution to understanding whether and how gender stereotypes impact people's decisions to help others (or not) lies in an integration of previously separate discussions of the distal and proximal psychological factors within a single conceptual framework from which testable hypotheses can be derived. We propose that, although patterns of gendered helping may be partially explained using existing theoretical models (e.g., the bystander intervention decision tree or the arousal cost-reward model), no systematic inquiry has directly explored the complex, individual-level psychological mechanisms that predict real-time decisions about whether to help another person, within the broader context of gender role expectations and stereotypes that influence everyday behaviors and motivations. And, perhaps most importantly, research has yet to examine how these processes could be shifted using social psychological interventions to initiate a feedback loop that has the potential to begin changing gender stereotypes, at first within the context of prosocial behavior, and then more broadly.

In outlining our integrative process model, we provide a brief review of existing models of engagement in prosocial behavior, then examine these models in a new light by considering the impact of both the distal and proximal effects of gender role stereotypes on people's 


\section{HELPING TO PROMOTE GENDER EQUALITY}

decisions of whether or not to help. Again, it is important to note that the scope of helping behaviors considered by our process model is limited to deliberate forms of everyday helping, whether enacted spontaneously or in response to a direct request. Examples from preliminary empirical studies on this work include helping someone jumpstart a car or helping someone carry a heavy item (stereotypically masculine forms of helping), and calling someone to cheer them up or offering someone moral support (stereotypically feminine forms of helping; citation masked for review). Our model does not intend to explain helping behaviors that are more heroic or automatic in nature, though those types of helping certainly occur in the real world. A key assumption of our model, in line with the broader models of prosociality summarized below, is that helpers often engage in conscious deliberation about whether to help and form an intention to behave based on a series of cognitive and affective processes, but we go further by considering the (likely involuntary) influence of gender stereotypes on these processes.

\section{Existing models of helping}

Social psychology has devoted many books and journal pages to explaining general, individual-level factors underlying when and why people decide to help others. The seminal bystander intervention decision model (Latané \& Darley, 1970) suggests that when an individual encounters a situation in which help is needed, they must successfully pass through several decision-making steps before they choose to intervene (e.g., challenging pluralistic ignorance, overcoming diffusion of responsibility, assessing the potential risk of danger or embarrassment in the event that they intervene). In other work, the arousal: cost-reward model of helping (Piliavin, Dovidio, Gaertner, \& Clark, 1981) suggests that potential helpers must also consider the risks involved with not helping. Specifically, this model suggests that, before deciding to help, people weigh the potential costs of helping (e.g., embarrassment, personal risk of danger or 


\section{HELPING TO PROMOTE GENDER EQUALITY}

harm, time costs) relative to both the potential rewards of helping (e.g., money, self-praise, gratitude from the receiver) and costs of not helping (e.g., feelings of guilt and shame; Dovidio \& Penner, 2001). Ultimately, in order to make a decision to help, people must decide the costs of helping are lower than the rewards and lower than the costs of not helping at all (Dovidio, Piliavin, Gaertner, Schroeder, \& Clark, 1991; Piliavin et al., 1981).

Many existing theories, such as these, offer insight into proximal, individual-level factors that promote/impede helping behavior, but to our knowledge, none of them speak directly to the importance of making these decisions within a broader context of gender role stereotypes. We argue that people are more likely to help in ways that align with gender role stereotypes because those stereotypes can automatically and unconsciously affect the specific psychological mechanisms that precede actual behavior, exerting influence at both distal and proximal levels.

\section{Distal factors that contribute to gender roles inhibiting prosociality}

The Social Role Theory (SRT) of helping clearly outlines the social structural processes by which gender roles lead to and reinforce patterns of gendered helping over time (Diekman \& Clark, 2015; Eagly, 2009; Eagly \& Crowley, 1986). To our knowledge, the SRT of helping is the only social psychological model of prosociality that explicitly and focally accounts for gender roles within its explanatory framework. Thus, our GRIP model is squarely built on SRT, as it sets the foundation for understanding the contextual (i.e., distal) factors that will ultimately lead to individual-level decision-making about whether to help (see Figure 1). As described earlier in this paper, SRT (Eagly, 1987) espouses that cultural beliefs about how men and women should behave (i.e., gender stereotypes) arise from observations of the social roles men and women typically hold within a society. 


\section{HELPING TO PROMOTE GENDER EQUALITY}

Applying SRT to the domain of prosociality, the stereotypical divisions in the various social roles that men and women occupy in Western societies directly cause stereotypical divisions in helping behavior (Eagly, 2009; Eagly \& Crowley, 1986). As people continue to engage in helping that is primarily consistent with gender role stereotypes (i.e., men doing agentic helping and women doing communal helping), there will be a continued cultural norm (i.e., stereotype) that men and women should do agentic and communal helping, respectively (see Figure 1 Paths A, G, \& H). Further, SRT emphasizes that these cultural norms will then become incorporated into a person's self-concept (i.e., shaping their gender identity), which is then used as a standard against which they regulate their own behavior, as well as the behavior of others (Eagly \& Wood, 2009). It is through these processes of internalization and regulation that cultural stereotypes come to impact an individual's attitudes toward, perceptions of the social norms about, and sense of their own ability to perform various helping behaviors (Wood \& Eagly, 2012). This leads to (and also reinforces) the continuation of stereotypical assumptions that men can and should do primarily agentic forms of helping and that women can and should do primarily communal forms of helping. Moreover, stereotypic gendered helping reinforces the broader system of gender stereotypes and divisions of behavior, far beyond prosociality. In the next section, we will delve deeper into the specifics of stereotype internalization processes, articulating more acutely how such ideas develop as we discuss the proximal factors that contribute to gender roles inhibiting prosociality.

SRT gives insight into the most obvious (and effective) way to increase genderinconsistent helping: large-scale change at a societal level (Diekman \& Clark, 2015; Eagly, 2009). In this sense, when social roles change and different groups of people start to occupy new roles, the corresponding stereotypes about people who make up those groups will also change. 


\section{HELPING TO PROMOTE GENDER EQUALITY}

Although behavior is certainly constrained by proximal factors (like gendered expectations, social norms, and beliefs about one's own abilities), research suggests that gender roles have become less rigid in recent decades, especially for women, but these changes have been slow and uneven, and appear to be stalling (e.g., Croft et al., 2015; Diekman \& Eagly, 2000; Eagly et al., 2020; England, 2010; England et al., 2020; Haines et al., 2016). Rather than waiting for largescale, systemic change (which could take decades, or even centuries), it would be productive for research to expand its scope to more directly incorporate key proximal, individual-level processes, especially those that can be targeted more readily by interventions. This will be especially useful if, as our GRIP model suggests, these individual-level changes in behavior can inform the broader social context and change the cycle through which gender stereotypes are derived (see Figure 1 Path H).

\section{Proximal factors that contribute to gender roles inhibiting prosociality}

As reviewed in existing models of helping, before a helper decides to provide assistance, they must first determine what type of help is needed, as well as assess potential consequences associated with helping (or not helping; e.g., Latane \& Darley, 1970; McGuire, 1994; Pearce \& Amato, 1980; Piliavin, Dovidio, Gaertner, \& Clark, 1981; Shotland \& Huston, 1979). The GRIP model integrates SRT with the Theory of Planned Behavior (Ajzen, 1991, 2011) to account for the individual-level psychological processes that lead to volitional choices about whether or not to help, including weighing the costs and benefits of helping that would violate traditional gender roles.

The TPB (Ajzen, 1991) has been applied extensively to predict health-related behaviors (e.g., physical activity, smoking cessation, healthy eating), but it is also a useful framework to understand decision-making processes with respect to gendered helping. The TPB (Ajzen, 1991, 


\section{HELPING TO PROMOTE GENDER EQUALITY}

2011) indicates that behavioral intentions (and subsequently, behavior itself) are predicted by a combination of three key factors: 1) attitudes toward the behavior; 2) beliefs about how other people will judge the behavior (subjective norms); and 3) ability/confidence to perform the behavior (self-efficacy). There is obvious overlap between these factors and the determinants of helping that have been identified in existing models of helping, such as the bystander intervention model. Our GRIP model (Figure 1) considers the TPB within the context of SRT to examine how each of these three factors is impacted by gender role stereotypes and to explain why people seldom engage in gender-inconsistent helping behavior (i.e., how each factor may block people from helping others in ways that go against traditional gender role stereotypes).

\section{Attitudes toward the behavior}

One key factor in predicting whether or not a person will engage in gender-inconsistent helping is their beliefs about the likely consequences of enacting the behavior (Ajzen, 1991, 2011). When people expect a given behavior to have negative consequences (e.g., make them feel bad), they form negative attitudes toward it (see Figure 1 Path B). It is easy to see how anticipating a negative outcome (whether it be negative, or merely less positive) when imagining a particular helping behavior could reduce the chances of providing help (see Figure 1 Paths E \& F).

The notion that people's attitudes about an anticipated outcome can influence how they act is in line with previous research showing that a person's affective forecasts are reliable predictors of their future behavior. Indeed, recent theorizing suggests that people contemplate engagement in future actions by reflecting and drawing upon emotional outcomes of prior actions, creating a feedback cycle of indirect emotion-driven behavior (e.g., Baumeister, DeWall, Vohs, \& Alquist, 2010; Baumeister, Vohs, DeWall, \& Zhang, 2007). Further, this process may 


\section{HELPING TO PROMOTE GENDER EQUALITY}

be automatic, leading people to seek and repeat actions and events that generated positive emotions, while avoiding those that brought about negative emotions (Baumeister et al., 2007). With respect to helping, this means that people's attitudes toward the behavior will be informed by their predictions of how they expect to feel if they helped.

Unfortunately, humans often lack insight in anticipating how various situations and behaviors will make them feel. The affective forecasting literature has documented how people make systematic errors in predicting the duration and extremity of their emotions (see Wilson \& Gilbert, 2003 for a review). For instance, people underestimate how good it will feel to put their best face forward when interacting with a stranger (Dunn, Biesanz, Human, \& Finn, 2007) and, relevant to the current paper, the emotional benefits that come from helping others (Dunn et al., 2008). People also underestimate how bad it will feel to do something that goes against their values. For example, people fail to anticipate how bad it feels to exact revenge (Carlsmith, Wilson, \& Gilbert, 2008), or to pursue extrinsic (vs. intrinsic) goals (Sheldon, Gunz, Nichols, \& Ferguson, 2010). Findings like these suggest that people probably underestimate not only how good it will feel to help others, but also how bad it will feel not to help in gender-inconsistent ways.

Social Role Theory (Eagly \& Wood, 2012) would predict that people form overly negative expectations about how gender-inconsistent helping will make them feel, which then become internalized as negative attitudes toward gender-inconsistent helping. In the absence of previous personal experience engaging in a certain behavior, such as gender-inconsistent helping, people must necessarily rely on abstract expectations (i.e., stereotypes) in order to forecast their potential future experiences and emotional outcomes (Brown \& Diekman, 2010; Croft, Schmader, \& Block, 2019). As explained by SRT, the content of these stereotypes comes 


\section{HELPING TO PROMOTE GENDER EQUALITY}

from observing who holds what roles (including "helper") in society (Dovidio \& Penner, 2001; Eagly \& Crowley, 1986). Consequently, traditional stereotypes governing men's and women's social behavior are likely to come into play when people anticipate how they will feel if they were to help. Given that women and men are socialized to behave in line with stereotypes that assume women are more communal and men are more agentic, they might mis-predict the degree and valence of their emotions (i.e., might not expect a favorable or pleasant outcome, or might even expect to feel bad) when they imagine engaging in a helping behavior that is inconsistent with their prescribed gender role. Moreover, we argue that this is likely to be the case even if people hold generally positive attitudes about helping others.

Few studies within the realm of anticipated affect and helping have specifically focused on the role of gender in this process. However, one study did measure men's and women's anticipated emotional rewards when envisioning helping within a stereotypically-feminine context (Sprecher, Fehr, \& Zimmerman, 2007). Participants in this study predicted their emotional reaction to helping a friend (e.g., expressing empathy and caring, providing care when sick, etc.). Results support our theorizing: women were more likely than men to expect positive feelings as a result of helping a friend in a female-stereotypic way. But this work did not examine whether men were more likely than women to expect positive feelings when imagining helping in male-stereotypic way. Our own empirical research, however, reveals that both men and women report more negative attitudes towards gender-inconsistent than gender-consistent helping (citation masked for review).

In summary, we propose that, because people lack experience with gender-inconsistent helping, and make systematic errors when forecasting how they will feel, they may not anticipate 


\section{HELPING TO PROMOTE GENDER EQUALITY}

experiencing the usual benefits and rewards associated with prosocial behavior (e.g., affective, reputational, etc.). These negative attitudes form one barrier to gender-inconsistent helping.

\section{Subjective norms}

The second proximal predictor of gendered helping in the GRIP model is subjective norms. Consistent with the TPB, subjective norms are an individual's perceptions of what others think they should or should not do, and they influence how people are perceived and judged by others (Ajzen, 1991). Gender role stereotypes dictate that women should be warm and kind, but should not be rebellious and stubborn, while in contrast, men should be self-reliant and assertive, but should not be emotional or weak (Prentice \& Carranza, 2002). SRT (Eagly, 1987; Eagly \& Wood, 2012) describes how these gender roles translate into norms about the types of helping men and women do. Norms are another key barrier to engagement in gender-inconsistent helping because people are reluctant to engage in types of helping that they do not see others doing, or that they think others will not approve of them doing (see Figure 1 Paths C, E \& F). For example, a man might have a positive attitude toward giving their friend a comforting hug, but opt not to do so because he is concerned about facing negative social judgments for violating traditional gender norms.

In general, previous research suggests that people who engage in roles incongruent with the norms prescribed for their social group are negatively evaluated, while those engaging in roles congruent with the norms prescribed for their social group are positively evaluated. This is explained by role congruity theory (Diekman \& Goodfriend, 2006; Eagly \& Karau, 2002), which proposes that differential value is placed on behaviors dependent on group membership and the degree to which stereotypes of that group align with the role. Put simply, applied to gendered helping behavior, role congruity theory would predict that prosocial behaviors in line with 


\section{HELPING TO PROMOTE GENDER EQUALITY}

communal expectations are likely to be perceived positively when enacted by women and negatively (or at least less positively) when enacted by men. Following a similar pattern, behaviors in line with agentic role expectations are likely to be valued more positively by others when enacted by men and more negatively when enacted by women.

Consequences for violating traditional gender roles range from negative evaluations to more tangible social and economic penalties. This backlash effect for gender role violations has been widely documented in the literature (e.g., Brescoll, Dawson, \& Uhlmann, 2010; Brescoll \& Uhlmann, 2008; Rudman, Moss-Racusin, Phelan, \& Nauts, 2012; Rudman \& Fairchild, 2004; Rudman \& Glick, 2001; Rudman \& Mescher, 2013; Rudman \& Phelan, 2008), and is a mechanism by which restrictive gender stereotypes are maintained and reinforced (Rudman et al., 2012; Rudman \& Fairchild, 2004). For example, women who violate gender stereotypes by possessing qualities considered masculine, such as assertiveness and independence, are rated as competent and strong leaders in the workplace, but are simultaneously rated as less likeable and less deserving of respect (Heilman \& Wallen, 2010; Rudman \& Glick, 2001). Likewise, when communal men violate masculine stereotypes they are perceived as warm and kind, but suffer consequences of the backlash effect by also being perceived as weak and low in agency (Heilman \& Wallen, 2010; Moss-Racusin, Phelan, \& Rudman, 2010).

Given the findings summarized in the previous paragraph, it is likely that helpers anticipate facing social backlash for violating gender roles when providing gender-inconsistent forms of help. We posit that people have an understanding of societal expectations for their behavior based on their gender roles, and this understanding results in a fear of deviation, constraining people from acting in a way that might lead others to judge them negatively. Given people's tendency to seek out and be hyper-vigilant for negative feedback cues from others when 


\section{HELPING TO PROMOTE GENDER EQUALITY}

feeling threatened (Forbes, Schmader, \& Allen, 2008; Jamieson \& Harkins, 2007), and to the extent that facing social backlash is a form of threat to the self, we argue that potential helpers might be wary of eliciting negative judgments from others if they were to help in genderinconsistent ways. Indeed, we find in our empirical studies that people think others will judge gender-inconsistent helpers more negatively than they claim to judge gender-inconsistent helpers themselves (citation masked for review). Regardless of the accuracy (see below for details) of people's concerns about backlash, however, these concerns likely lead to a fear of violating subjective gender norms and dissuade people from engaging in gender-inconsistent helping behavior when given the chance.

\section{Self-efficacy}

The final proximal predictor in the GRIP model is a person's subjective belief that they can effectively complete the behavior in question, which is likely to be informed by cultural stereotypes about what behaviors are appropriate for one's gender category. For example, a woman might have a positive attitude toward helping someone with a dead car battery, and not be concerned about facing social sanctions from others for violating traditional gender norms, but nonetheless opt not to help because she lacks a sense of confidence in her skill or ability to help in that (stereotypically masculine) context (see Figure 1, Paths D, E, \& F). As explained by SRT (Eagly \& Wood, 2012), gender stereotypes send a strong signal that women are less apt than men at doing car-related tasks and so a woman may conclude that she is incapable of helping to jump-start a car despite (we humbly suggest) having equal opportunity to pursue the realistic option of conducting a quick Internet search for step-by-step instructions with pictures, rendering her equally capable of at least attempting to help. 


\section{HELPING TO PROMOTE GENDER EQUALITY}

One of the ways in which individuals might fail to develop a sense of self-efficacy for gender-inconsistent helping is through early socialization and internalization of traditional gender role expectations. Recent research and theorizing argues that young children's experiences are deeply influenced by stereotypes of girls and women as being communal and other-oriented, and boys and men as being agentic and self-focused (see Croft et al., 2015 for a detailed review of this process). This heavy gender stereotype influence on childhood development can lead boys and girls to adopt a self-view that is in line with such beliefs to the extent that they even display implicit or automatic levels of self-stereotyping (Baron, et al., 2014; Block, Gonzalez, Schmader, \& Baron, 2018). Over the span of a lifetime of conceptualizing oneself through the lens of a particular gender identity category (i.e., primarily male or female), a person would also come to perceive their own skills and ability levels to be consistent with those of their gender (Baron et al., 2014; Diekman \& Eagly, 2000). A person could easily conclude that they do not have the skills that are inconsistent with their gender, and essentialize these limitations to the extent that they come to believe that it would not be possible to develop those skills. With respect to prosocial behavior, men and women may come to believe that they are only capable (or at least more capable) of performing helping behaviors that are prescribed to their ingroup. As a consequence, people might infer that they are less capable of helping someone in a gender-inconsistent way. Further, if people attempted to help in a genderinconsistent way, they might expect it to require considerably more effort than it would for a helper of a different gender, and fear they will be unsuccessful. Consistent with this argument, in our own empirical studies, we find that people predict higher self-efficacy when they imagine helping in a gender-consistent versus -inconsistent way (citation masked for review). 


\section{HELPING TO PROMOTE GENDER EQUALITY}

The GRIP model focuses on self-efficacy, which is just one of the internal aspects of the broader TPB factor labeled perceived behavioral control (Ajzen, 2002). It is important to note, however, that there is an external aspect of perceived behavioral control that could also impact a person's likelihood of engaging in gendered helping: physical or biologically-based differences between the sexes. Men's larger size and greater strength, which are products of biology more than socialization, do make them better suited to feats of heroism and physically risky types of helping, relative to women (Becker \& Eagly, 2004; Eagly, 2009). It also seems likely that helping based on automatic reactions could be more closely tied to biological sex differences than helping behaviors stemming from conscious deliberation and an active choice to help (e.g., sex differences in spatial reasoning ability might favor men's capacity to make snap judgements about whether it is safe to jump in front of a moving vehicle to save someone).

As described earlier, the kinds of everyday helping our model is designed to predict are conscious, deliberate, and, we argue, less subject to biologically-based sex differences in ability. We have chosen to focus on gender (not sex) differences that are almost certainly an artifact of cultural stereotypes, such as socioemotional ability (e.g., Allen \& Smith, 2011; Bosson, Haymovitz, \& Pinel, 2004; Ickes, Gesn, \& Graham, 2000; Koenig \& Eagly, 2005; Leyens, Desert, Croizet, \& Darcis, 2000). As mentioned in the earlier section on communal forms of helping, past research has shown that men and women both prefer to receive emotional support from women. This preference suggests a general (and perhaps unconscious) endorsement of the stereotype that women are more effective at this kind of helping (Burleson \& Kunkel, 2006), but does not provide evidence that there are realistic sex differences in this skill. If anything, this preference might indicate that women are more likely than men to be explicitly asked to provide emotional support and, therefore, women (relative to men) have a greater number of 


\section{HELPING TO PROMOTE GENDER EQUALITY}

opportunities to practice and improve their capacity to help successfully in this way. But this need not be the case. With enough practice and conscious effort, men may feel increasingly capable of providing emotional support, thereby reducing hesitation and ultimately engaging more in this type of helping behavior.

In summary, societal gender roles take hold early in development, leading people to feel as if they lack the skills needed to perform roles that are not aligned with their gender. Feeling as if one lacks the ability to help creates a proximal barrier to gender-inconsistent helping.

\section{Loosening the GRIP to Promote Gender Equality}

Having described the key distal and proximal factors of our GRIP model, we consider why and how helping is an ideal context to begin shifting broader gender stereotypes and loosening harmful cultural norms that restrict behavior and opportunities (see Figure 1 Path $\mathrm{H}$ ). First, we review the literature highlighting the special characteristics of prosocial behavior that explain why it is a particularly fruitful entry point for efforts to increase gender equality more broadly. Then, we describe how these features of prosocial behavior should make it a tractable target for behavioral change, using the proximal pathways of the GRIP model to derive interventions that could be harnessed to cultivate gender equality. Finally, we draw on the distal pathways of the GRIP model to provide a detailed account of how the promotion of increased engagement in gender-inconsistent helping could result in broader changes in gender stereotypes.

\section{Special characteristics of prosocial behavior}

Prosocial behavior may prove to be an especially useful entry point for shifting gender stereotypes because people who help others enjoy myriad benefits. As such, we theorize that people should generally hold positive attitudes towards helping (in any form). Further, because helping is valued cross-culturally for both men and women, and engaging in gender-inconsistent 


\section{HELPING TO PROMOTE GENDER EQUALITY}

forms of helping is unlikely to threaten the existing gender status hierarchy or elicit social backlash, we also suggest that people should perceive the social norms surrounding prosocial behavior to be supportive (rather than restrictive) and feel empowered by their ability to help someone in need, regardless of gender role expectations.

\section{Helping benefits the helper}

People who help others are happier. Research from diverse samples and in various countries has shown both correlational and causal links between prosocial actions and subjective well-being outcomes (e.g., Aknin, Broesch, Hamlin, \& Van de Vondervoort, 2015; Aknin et al., 2013; Aknin, Dunn, Proulx, Lok \& Norton, 2020; Borgonovi, 2008; Dunn, Aknin, \& Norton, 2008; Haski-Leventhal, 2009; Lyubomirsky, Sheldon, \& Schkade, 2005; Nelson, Layous, Cole, \& Lyubomirsky, 2016). For instance, students randomly assigned to commit five kind acts in a single day each week for six weeks were significantly happier than a control group (Lyubomirsky et al., 2005). More recently, a sample of students and community members reported significantly higher levels of happiness and meaning in life after engaging in prosocial action directed toward others or the world than after treating themselves for six consecutive weeks (Nelson et al., 2016). Indeed, a recent meta-analysis of 27 experimental studies $(N=$ 4,045) suggests that helping has a small but reliable impact on well-being (Curry et al., 2018). While few (if any) studies have directly examined whether gender moderates the emotional rewards of prosocial action, large experiments investigating this question include both men and women and typically detect hedonic benefits of generosity, suggesting that this finding is likely present to some extent in both men and women.

Helping others satisfies the human need to belong, resulting in helpers feeling more socially connected (Baumeister \& Leary, 1995). Past work has identified social relationships as a 


\section{HELPING TO PROMOTE GENDER EQUALITY}

key predictor of well-being and a necessary requirement for achieving the highest levels of happiness (Diener \& Seligman, 2002; Helliwell, Huang \& Wang, 2019). To the extent that this finding is rooted in our evolutionary history - in which reliable social bonds assisted with food, safety, and survival, and provided the general pleasure derived from strengthening meaningful social bonds - it is unlikely to differ greatly between men and women.

The emotional benefits that result from generous action are often underestimated. While people seem to realize that helping others leads to positive emotion (e.g., Andreoni, 1990;

Cialdini, Darby \& Vincent, 1973; Harris, 1977), people also state that prioritizing their own selfinterest can be more rewarding. For instance, in one study, students were asked to indicate whether they would be happier spending money on themselves or others (Dunn et al., 2008). The significant majority stated that they would be happier spending on themselves, despite the finding that a separate group of students reported greater well-being after spending on others than on themselves (Dunn et al., 2008). This pattern aligns with a common tendency to believe that people are generally self-interested, which then becomes a self-reinforcing notion driving people to act in ways that pursue their own benefit because they expect that they should behave as others (ostensibly) do (Miller, 1999). Thus, while people seem to have a general notion that helping leads to happiness, they tend to overlook or, at least, underestimate the hedonic rewards.

Cross-cultural work has shown that behaving prosocially is widely regarded as a positive activity in nearly all societies (e.g., House et al., 2013; Klein et al., 2015), and people who are generous with others garner prestigious reputational rewards (e.g., Willer, 2009; Willer, Feinberg, Irwin, Schultz, \& Simpson, 2010). Indeed, this is why prosociality is special, relative to other positively-valenced behaviors (such as leadership or caregiving), because it is socially valued for everyone; helping is positive when men do it and when women do it. This is not true 


\section{HELPING TO PROMOTE GENDER EQUALITY}

for other contexts in which we might endeavor to promote greater equality, because they are so asymmetrically gender-typed that enacting the behavior is only viewed positively for one gender group. Thus, the seemingly universal value placed on prosociality means that helping of any kind, by anyone, is likely to be seen in a positive light. For instance, in a series of studies conducted by Willer (2009), participants were randomly assigned to interact with a fictitious individual who had either invested higher or lower amounts of money in a group task. Participants randomly assigned to work with someone who had displayed higher (vs. lower) levels of generosity rated this person as significantly more honorable, prestigious, and respected, a finding that was mediated by perceptions of other-concern. Indeed, participants not only attributed high status to more generous actors, but they found these individuals more influential, in that they were more likely to adopt the generous actor's suggestion when they disagreed (Willer, 2009). Recent work reinforces the influence of generous or otherwise helpful behavior in what might be typically aggressive contexts, such as bargaining or negotiation situations. Generous first offers build greater trust with recipients, leading recipients to disclose vulnerable, valuable, and potentially harmful information (Jeong, Minson \& Gino, 2020). Thus, helpful behavior can provide a number of reputational and practical advantages to an actor.

\section{Helping is valuable and unlikely to elicit social backlash}

Regardless of the potential for helpers to garner personal benefits as a side-effect, helping is unique because it is inherently other-oriented and not self-serving; helpers' motives are generally altruistic (e.g., Konrath, Fuhrel-Forbis, Lou \& Brown, 2012). Accordingly, helping is unlikely to threaten the existing gender status hierarchy: We theorize that women do not gain status by helping because it is not generally associated with a motivation for personal gain (i.e., it is not agentic), and men do not lose status by helping because it is viewed as valuable (i.e., it is 


\section{HELPING TO PROMOTE GENDER EQUALITY}

less subject to masculinity threats because it does not require men to sacrifice their agency). Therefore, we argue, gender-inconsistent helping should be less likely to elicit the degree of backlash that typically follows violations of gender stereotypes. Further, this lack of backlash should be conceptually distinct from other processes that elicit threats to the status quo (the "way things are"), because any change to predominant cultural norms, such as expectations for adherence to gender stereotypes, will (by definition) upend the status quo.

Our argument is supported by the Status Incongruity Hypothesis (SIH; Moss-Racusin et al., 2010; Rudman et al., 2012), which explores the conditions under which people face social backlash when they violate traditional gender roles (e.g., women entering leadership roles). According to SIH, social backlash functions to maintain the existing gender hierarchy by relying on people to police women who seek more power and men who relinquish their power (MossRacusin et al., 2010; Rudman et al., 2012; Rudman \& Fairchild, 2004). Empirical tests of SIH reveal that women face backlash for behaving too dominantly (a proscription for women), and men face backlash for behaving insufficiently agentic (a prescription for men) or appearing too weak (a proscription for men; Moss-Racusin et al., 2010; Prentice \& Carranza, 2002; Rudman et al., 2012).

To our knowledge, only a handful of studies have examined perceptions of helpers who violate gender roles, and the results appear to be mixed in terms of how helpers are perceived. Congruent with our theorizing, evidence indicates that violations of gendered norms in the context of helping do not always result in backlash. Indeed, some studies find that men and women who help in ways that are inconsistent with gender roles are actually perceived more favorably than their gender-consistent counterparts (e.g., Heilman \& Chen, 2005; Taynor \& Deaux, 1973). For instance, in a study examining perceptions of men and women who engage in 


\section{HELPING TO PROMOTE GENDER EQUALITY}

stereotypically feminine workplace organizational citizenship behaviors (e.g., helping a coworker after hours, at a personal cost), Heilman and Chen (2005) found that male helpers received more favorable evaluations than female helpers. A similar pattern has been documented for perceptions of women engaging in stereotypically masculine helping behaviors. When examining perceptions of a man or woman helping in a civic emergency, participants rated female helpers as more deserving of a reward and evaluated their performance more favorably than male helpers' (Taynor \& Deaux, 1973). Thus, both men and women can sometimes receive praise - rather than backlash - for helping in ways that violate gender stereotypes.

One possible explanation for these counterintuitive findings is that the success standards for gender-inconsistent helping are set lower than those for gender-consistent helping. In other words, the bar for successful helping in unexpected (e.g., gender-inconsistent) ways is set at a lower threshold compared to the bar for successful helping in expected (e.g., gender-consistent) ways. This theorizing is consistent with research on the shifting standards model (Biernat \& Manis, 1994), which explains why people enacting identical behaviors may be perceived differently based on their demographic characteristics. When evaluating a target, perceivers consider a target's behavior as well as attributes about the target, such as their gender, and may shift their standards of judgment based on stereotyped expectations. Within the context of gendered helping, perceivers may evaluate a man and a woman offering emotional support—a stereotypically feminine helping behavior-differently due to shifting standards of judgement. A woman helping someone by offering emotional support could very well be judged positively and seen as helpful, but a man engaging in the same behavior might be judged even more positively and seen as even more helpful simply because the perceiver set lower standards for his success. 


\section{HELPING TO PROMOTE GENDER EQUALITY}

Regardless of why people praise men and women for gender-inconsistent helping, data suggest that backlash is not inevitable.

Our own empirical work also suggests reduced social costs (e.g., negative judgements) when it comes to perceptions of gender-inconsistent helpers. Unlike the studies described above, however, we did not observe evidence of overly positive evaluations of gender-inconsistent helpers, but there was a discrepancy between people's own ratings of gender-inconsistent helpers and their predictions about how other people would evaluate these helpers (citation masked for review). Specifically, people expected others to show social backlash toward gender-inconsistent helpers (versus gender-consistent helpers), despite not displaying social backlash themselves.

Further support for our argument that gender-inconsistent helping should be less susceptible to backlash (relative to other gender role violations) comes from a recent metaanalysis examining negative reactions to women's explicit displays of dominance (Williams \& Tiedens, 2016). A key conclusion from this meta-analysis is that ratings of women's warmth only declined when the women enacted dominance displays that were construed as explicit gender role violations (e.g., making direct demands) as opposed to displays that were more subtle or implicit (e.g., making eye contact). Integrating this finding with the rationale underlying SIH (Moss-Racusin et al., 2010; Rudman et al., 2012), perhaps backlash occurred primarily in response to these explicit dominance displays because they are more proscriptive for the female gender role than subtle dominance displays. In terms of helping, although communal behaviors are generally proscriptive for the male gender role, this conflicts with the fact that helping is prescriptive for both men and women. We suggest, then, that backlash is unlikely to occur to the same degree. It will be important for future research to examine this proposition 


\section{HELPING TO PROMOTE GENDER EQUALITY}

empirically by comparing rates of social backlash for gender role violations in the domain of helping relative to other (non-prosocial) contexts.

Taken together, helpers should hold positive attitudes towards prosocial behavior to the extent that they anticipate at least some of the positive consequences of helping, and they should expect the norms around helping in general to be positive, given that prosociality is viewed positively by others. However, people typically have negative attitudes towards gender role violations (e.g., Rudman \& Fairchild, 2004) and may expect the norms for gender role-violating behaviors to be negative. Thus, when people consider helping in gender-inconsistent ways, they must reconcile these conflicting attitudes and norms. The unique characteristics of helping make it a particularly powerful context for challenging gender stereotypes more broadly. The GRIP model suggests that it should be possible to increase gender-inconsistent helping by (a) enhancing positive attitudes toward gender-inconsistent helping, (b) assuaging people's fears that they will face negative judgments from others, and (c) fostering a sense of skill and capability among people who violate gender stereotypes in order to help someone. In the next section of the paper we explore each of these components in detail. We then make the case that intervening in these individual-level psychological processes should lead to subsequent changes in broader cultural processes related to gender stereotyping via the mechanisms outlined by Social Role Theory (SRT; Eagly \& Wood, 2012). See Table 1 for a summary of hypothesized interventions and their underlying rationale.

\section{Increasing gender-inconsistent helping at the proximal level}

\section{Enhancing positive attitudes toward gender-inconsistent helping}

The GRIP model proposes that people are less likely to engage in gender-inconsistent helping when they hold less positive attitudes toward these behaviors (e.g., underestimate how 


\section{HELPING TO PROMOTE GENDER EQUALITY}

emotionally rewarding it will be, overestimate how uncomfortable it will be; see Figure 1, Paths B, E, \& F). Making such errors when forecasting one's predicted affect is understandable, given that people must rely on stereotyped expectations in the absence of lived experience.

Anticipating how one might feel after violating gender roles to help someone, however, might be especially inaccurate (and, therefore, especially correctable) relative to other domains in which someone anticipates behaving in a way that is counter-stereotypic. This is because, unlike most other gender role violations (e.g., women entering STEM occupations), there are immediate rewards in the form of gratitude and social connectedness that contribute to a boost in positive affect following an act of helping. If people base their attitudes on forecasts that focus more on the potential negative (versus the potential positive) outcomes of gender-inconsistent helping, then effective interventions could target this mechanism.

When people predict how they will feel after helping in gender-inconsistent ways, they might disproportionately focus on the negative effects of acting in a counter-stereotypical way, and neglect to take into account some of the potential positive effects that come from helping others. Indeed, errors in affective forecasting have been explained, in part, by focalism (Wilson, Wheatley, Meyers, Gilbert, \& Axsom, 2000), a phenomenon in which people tend to focus on a specific event (e.g., winning the lottery), and neglect everything else that is happening at the same time (e.g., dealing with health concerns or difficult relatives). Building on this rationale, we propose two hypotheses for future research that should counteract focalism, and thus interrupt the process by which the fear of negative outcomes prevents people from helping others in ways that are gender-inconsistent: 1) helping people broaden their focus when thinking about helping (e.g., reminding people to reflect on how they will feel if they fail to help when help is needed); 


\section{HELPING TO PROMOTE GENDER EQUALITY}

and 2) encouraging people to focus on how they can positively impact the person they are helping, rather than focusing on their own concerns about transgressing stereotypes.

One way to interrupt negative-leaning forecasting errors around gender-inconsistent helping is to encourage people to think about other things too, thereby broadening their thinking. Research has used this strategy to improve affective forecasts about exercise. Given that the beginning of an exercise routine is often the most unpleasant, asking people to spread their attention by thinking about how they would feel at the beginning, middle and end of an exercise routine makes estimates of overall enjoyment more positive and more accurate, and increases intentions to exercise (Ruby et al., 2011). Although not completely analogous, asking people to think of how they will feel before, during and after gender-inconsistent helping might remind people of the good feelings that come from helping, and increase their intentions to help in the future (Aknin, Dunn, \& Norton, 2012). Essentially, this intervention would attempt to shift attention from the dread of what might happen if one were to violate gender role stereotypes to a realization of feeling good after helping.

In addition to highlighting the benefits of helping, this strategy might also work by making salient the potential for anticipated regret in the event that people choose not to help someone. Beyond simple anticipation of a good or bad outcome, researchers identified anticipated regret as a powerful motivational force in forming behavioral intentions (e.g., Abraham \& Sheeran, 2003, 2004; Morison, Cozzolino, \& Orbell, 2010; Orbell \& Hagger, 2006; Rapaport \& Orbell, 2000; Sandberg \& Conner, 2008; Sheeran \& Orbell, 1999). Just as people feel grateful when induced to imagine that a positive event had never happened (Koo, Algoe, Wilson, \& Gilbert, 2008), they might anticipate regret when induced to imagine not helping. Indeed, the thought of ignoring or refusing a help request may spur anticipatory guilt that could 


\section{HELPING TO PROMOTE GENDER EQUALITY}

motivate helpful action (O’Keefe \& Figgé, 1997). Moreover, research also shows that people overestimate how much regret they will feel (Gilbert, Morewedge, Risen, \& Wilson, 2004), a tendency that could be harnessed in intervention studies (see Table 1 Intervention 1). Both of these avenues for future research have the potential to shift attitudes, and thus increase genderinconsistent helping.

A second possible intervention to reduce people's negative attitudes toward genderinconsistent helping is to redirect their attention away from the self and onto the person in need of help (see Table 1 Intervention 2). Past research indicates that people are more likely to engage in helpful behavior when considering how their actions will have a clear, positive impact on others (e.g., Grant, 2012; Grant \& Gino, 2010; Small \& Loewenstein, 2003; Smith, Keating, \& Stotland, 1989). Indeed, simply providing tangible details about how one's help will assist others has been found to bolster charitable donations (Cryder, Loewenstein, \& Scheines, 2013). Thus, to the extent that the possibility of engaging in gender-inconsistent helping leads people to focus on the potential negative consequences for themselves, an intervention that provides clear reminders of how a person's help will have a positive impact on the recipient (again, shifting focus away from the self) should be effective in changing attitudes.

In sum, we maintain that by changing people's expectations about how they will feel as a result of engaging in gender-inconsistent helping - in ways that emphasize the benefits of helping, both to themselves and the person being helped, and also highlight the regret they could feel as a result of not providing help - could shift their attitudes, thus boosting intentions and willingness to help. Despite the fact that an in-depth analysis from the perspective of the recipient of help is beyond the scope of this paper, we acknowledge that the recipient's reaction to the helper is likely to introduce additional layers of complexity. For instance, research 


\section{HELPING TO PROMOTE GENDER EQUALITY}

suggests that people do not always appreciate receiving help from others, especially if it is unsolicited (e.g., Nadler \& Fisher, 1986; Nadler \& Halabi, 2015; Sandstrom, Schmader, Croft, \& Kwok, 2019). Thus, while it is possible that a recipient of help might have a negative response (with the potential to sour the helper's experience accordingly), we reason that the odds of this outcome are sufficiently low - most people are likely to respond to being helped with gratitude.

Although similar interventions could target other behaviors that are restricted by gender role stereotypes, helping may be an especially tractable behavior to target. First, people should already hold positive attitudes toward helping, due to its many benefits, so these are available to be harnessed and amplified. Second, because helping involves another person, the benefits include feelings of having a positive impact on others, as well as building the social relationships that fulfill the fundamental human need to belong.

\section{Assuaging fears about social backlash for gender-inconsistent helping}

The second proximal barrier to gender-inconsistent helping outlined by our GRIP model is restrictive subjective norms - or a concern that other people will judge a gender-inconsistent helper negatively because that helper violated traditional gender stereotypes. In general, people are helpful and approve of helping, and these descriptive and injunctive norms (Cialdini, Kallgren, \& Reno, 1990) should be easily perceived. However, if people worry about facing the backlash that is common for other gender role violations, they might perceive the norms around

gender-inconsistent helping to be more restrictive, and limit this kind of helping accordingly (see Figure 1, Paths C, E, \& F).

Pluralistic ignorance might underlie people's concern about others' reactions to genderinconsistent helping. Pluralistic ignorance occurs, generally speaking, when a person privately rejects a social norm, but falsely assumes others accept it (Allport, 1924; Prentice \& Miller, 


\section{HELPING TO PROMOTE GENDER EQUALITY}

1996), and such a discrepancy has implications for behavior and sustaining social norms. With respect to gendered helping, this would be reflected in discrepancies between how people expect others will evaluate helpers who violate gender roles (e.g., expect that others will judge these helpers harshly, because others accept the stereotypes) versus how they actually evaluate such helpers (e.g., expect that they themselves will judge the helpers favorably, because they reject the stereotypes). This is exactly what we have found in our own research (citation masked for review). Specifically, we asked participants to report their own evaluations and their estimations for the evaluations of others (normative evaluations) of gender-consistent and genderinconsistent helpers. In two studies, we found that people expected others to judge genderinconsistent helpers less favorably than they did in their own evaluations. In other words, people erroneously expected others to view gender-inconsistent helping less favorably than they actually did. Using the GRIP model, we reason that people's inaccurate perceptions of the subjective norms surrounding gender-inconsistent helping form a barrier to engagement in these forms of helping. If people (falsely) think others will exhibit backlash against gender-inconsistent helpers, then they might avoid helping in gender-inconsistent ways out of fear of negative judgments from others.

Previous research in gendered domains other than helping finds that pluralistic ignorance results in people restricting their behavior (e.g., Munsch, Ridgeway, \& Williams, 2014; Munsch, Weaver, Bosson, \& O’Connor, 2018; Van Grootel, Van Laar, Meeussen, Schmader, \& Sczesny, 2018). For instance, workplace flexibility programs, which offer adjustable work hours and deadlines to accommodate family obligations, are of immense importance to women's advancement in the workplace. When examining perceptions of such programs, researchers found that people privately view workplace flexibility programs favorably, but they anticipate 


\section{HELPING TO PROMOTE GENDER EQUALITY}

others will evaluate the programs negatively, ultimately making them less likely to take advantage of such programs (Munsch et al., 2014). Furthermore, in another study examining endorsement of "masculinity contest norms" in the workplace (e.g., competition, dominance), workers perceived that others endorse such norms more so than they actually do (Munsch et al., 2018), and this discrepancy negatively impacted job satisfaction and engagement. Thus, we propose to reduce the barrier that norms pose to gender-inconsistent helping by showing people that their fears about social judgments are overblown, and out of line with the actual judgments of others.

Armed with support from the Status Incongruity Hypothesis (SIH; Moss-Racusin et al., 2010; Rudman et al., 2012) and a lack of actual social backlash against gender-inconsistent helpers (citation masked for review), we suggest two potential avenues for intervention: 1) reducing the effect of norms on behavior by educating helpers that others are not paying as much attention to them as they think; 2) helping people see that the norms are more positive than they might think (e.g., addressing pluralistic ignorance), by reminding helpers that even if others are paying attention, they might 2a) not actually display backlash against helpers who violate gender stereotypes; $2 b$ ) empathize with their situation, and even judge them positively rather than negatively; and 2c) be willing to help in gender-inconsistent ways themselves.

As a starting place for examining the foundation of helpers' worries, it is worth asking whether observers actually notice helping-related gender norm violations. Research on the spotlight effect finds that people tend to think others are paying more attention to them in everyday life than they actually are (Gilovich \& Savitsky, 1999; Gilovich, Medvec, \& Savitsky, 2000). Further, people predict that others' judgments of them will be more variable than they actually are. Specifically, people are finely attuned to changes in their own appearance and 


\section{HELPING TO PROMOTE GENDER EQUALITY}

performance, and because predictions about others' perceptions are anchored in perceptions of themselves (Epley, Keysar, Van Boven, \& Gilovich, 2004), people overestimate the extent to which others notice these changes too (Gilovich, Kruger, \& Medvec, 2002). For example, someone might think they are having a "bad hair day," because they compare their own hair on that day to how it looked on other days, whereas others are less likely to notice subtle day-to-day differences. Thus, within the context of gendered helping, people may feel like others notice their gender-inconsistent helping (i.e., a change from their usual behavior) more than they actually do. There is also evidence that people think others notice their stigmatized characteristics more than they actually do. When someone is the only member of an ethnic minority, or the only member of their gender in a group, and attention is brought to their ethnicity or gender, people feel like others are looking at them more, and this makes them experience more negative affect (Crosby, King, \& Savitsky, 2014). No research to date has investigated the extent to which gender-inconsistent helping is even noticed and flagged as a norm violation. It might be possible to reduce the effect of norms on behavior, and thus encourage more gender-inconsistent helping, by teaching people about the spotlight effect (see Table 1 Intervention 3). This may be especially effective for helping behaviors because of their general positivity; others may notice that someone is helping, but not notice the more subtle fact that the helping is gender-inconsistent.

A second intervention goes beyond whether or not others are paying attention to helpers and focuses on helpers' accuracy in expecting others to negatively judge them (see Table 1 Intervention 4a). As described above, sometimes people are mistaken about the direction of another person's attitudes (e.g., thinking they have positive attitudes towards competition at work, when in fact they have negative attitudes). This particular form of pluralistic ignorance 


\section{HELPING TO PROMOTE GENDER EQUALITY}

occurs when a person avoids a behavior for one reason, but underestimates the extent to which others share the same reason, instead attributing others' avoidance of the same behavior to other reasons (Miller \& McFarland, 1987). For example, people do not initiate interactions with others (e.g., strangers, members of an outgroup) because they worry about facing rejection and assume others do not initiate interactions because they are disinterested, rather than realizing others might share the same fears (Epley \& Schroeder, 2014; Shelton \& Richeson, 2005). It is possible that people might think others avoid engaging in gender-inconsistent helping because they consider it inappropriate, but really others avoid engaging in gender-inconsistent helping because they too fear disapproval. Again, our own research in this area has revealed support for this possibility; people's own evaluations of gender-inconsistent helpers are significantly less negative than the harsh judgments people expect others to make of the helpers (citation masked for review). Given research showing that people will shift away from gender-stereotypic outcomes when they are made aware of changing norms (e.g., Croft et al., 2019; van Grootel et al., 2018), this approach should work similarly to increase gender-inconsistent helping.

A third way to temper the tendency to overestimate the harshness of others' judgments is to remind people that others are likely to empathize with their situation. In one study, thinking first about the extent to which another person would be able to "empathize with the difficult situation you were in ... or imagine being 'in your shoes"” resulted in people expecting to be judged more charitably (Epley, Savitsky, \& Gilovich, 2002). The failure to realize the degree to which others empathize with oneself may be driven by the fact that people fail to realize just how similar they are to others (Mallett, Wilson, \& Gilbert, 2008). Thus, to target gender-inconsistent helping, one could start with an intervention to demonstrate that others of the same sex would also be likely to help (i.e., demonstrate similarity), and therefore be likely to empathize with 


\section{HELPING TO PROMOTE GENDER EQUALITY}

someone else who helped in the same way, especially since helping is universally valued (see Table 1 Intervention $4 \mathrm{~b}$ ). This approach is supported by past work on the effectiveness of role modelling such that seeing similar exemplars successfully enacting a behavior promotes interest in and likelihood of engaging in that same behavior (e.g., Asgari, Dasgupta, \& Cote, 2010; Stout, Dasgupta, Hunsinger, \& McManus, 2011).

Finally, people might perceive norms to be less restrictive if they witness others helping in gender-inconsistent ways. Participants could be asked to solicit help from someone of the opposite sex (e.g., women could ask a man for emotional support, or men could ask a woman for help with their electronic device; see Table 1 Intervention 4c). Given that perceptions of norms are often assessed by asking a person whether close others actually do a behavior or approve of a behavior, this intervention might be strongest if people asked for help from someone close to them, but it could also be tested with strangers in a lab context. Even strangers are extremely likely to comply with a direct request for help. In fact, people comply more than half the time, even when asked to do things like lie or vandalize a library book (Bohns, 2016). This is true even when the help is effortful because people are uncomfortable disappointing help-seekers (Newark, Bohns \& Flynn, 2017); gender-inconsistent helping might well be perceived as effortful, because it is counter-stereotypical. Thus, if participants ask for and receive gender-inconsistent help, especially if it comes from someone close to them, it should shift their perception of the norms around gender-inconsistent helping.

Alternatively, an intervention could encourage people to notice that gender-inconsistent behaviors are already happening all around them (see Table 1 Intervention 4c). Indeed, in two of our empirical studies, participants report engaging in a variety of gender-inconsistent helping behaviors on average one or two times each month (citation masked for review), suggesting that 


\section{HELPING TO PROMOTE GENDER EQUALITY}

these behaviors are ripe for observation. Classic research on the availability heuristic suggests that simply drawing attention to gender-inconsistent helping could increase its perceived frequency (Schwarz et al., 1991), leading observers to follow suit and engage in this behavior more often. Future studies could start to address this by examining correlational patterns between the number of times people report having observed gender-inconsistent helping (measured in a pre-test) and their own level of helping engagement within an orchestrated lab situation.

In sum, the second barrier to gender-inconsistent helping - restrictive subjective norms might also be fairly straightforward to overcome. Interventions aimed at dismantling people's fears of negative evaluation (using the strategies suggested here) provide promising directions for future research to promote gender-inconsistent helping. Moreover, challenging restrictive subjective norms around gender-inconsistent helping might also feed back into people's attitudes towards such helping because calling their subjective norms into question could lead people to anticipate more positive outcomes when forecasting how they would feel after helping. To the degree that fear of social backlash contributes to negative attitudes around gender-inconsistent helping (as is likely to be the case), removing those fears seems critically important.

\section{Fostering skills and confidence around gender-inconsistent helping}

The third barrier to gender-inconsistent helping outlined in our GRIP model is a lack of self-efficacy around helping in ways that cross traditional gender boundaries (see Figure 1, Paths D, E, \& F). As SRT suggests, people are typically socialized in line with cultural gender stereotypes starting very early in life and these stereotypes become internalized into people's self-concept, thereby gendering how one views their own skills and abilities (Wood \& Eagly, 2012). Here again, we propose that helping is a unique context for overcoming barriers to gender-based differences in self-efficacy because most forms of everyday helping encompass 


\section{HELPING TO PROMOTE GENDER EQUALITY}

acts that most people can already do, or could do using readily available technologies (e.g., quickly searching "how to" on a smart phone), unlike the deeper level of skill and training necessary to enter a counter-stereotypic occupation.

It is worth acknowledging, however, that there may be individual differences in the degree to which someone perceives they have successfully performed stereotypically masculine and feminine helping behaviors. The agentic/masculine forms of everyday helping we focus upon appear to be more dichotomous in nature (i.e., you either jumpstart a car or do not). The communal/feminine behaviors, however, are more nuanced. It may be more difficult to know whether or not you have successfully comforted someone, as different situations call for different emotionally supportive behaviors (e.g., some situations call for hugging someone and holding their hand, whereas other situations involve verbally processing emotions with another person), and people prefer different kinds of emotional support (e.g., someone might like a hug whereas someone else might just want an opportunity to vent). Therefore, it could be that people perceive stereotypically feminine helping behaviors as more difficult to learn, or to successfully accomplish. We are not aware of any research that has examined perceptions of the perceived difficulty of learning and performing stereotypically masculine and feminine helping behaviors, and this research will be important for informing interventions to increase gender-inconsistent helping self-efficacy. Regardless of these important considerations, we still reason that helping is a model context for undermining gender stereotypes because it can foster a greater sense of skill and capability and ultimately empower people to help in ways that violate traditional gender stereotypes.

To promote greater self-efficacy for gender-inconsistent helping, we propose inducing people to carry out simple gender-inconsistent helping tasks (see Table 1 Intervention 5). Given 


\section{HELPING TO PROMOTE GENDER EQUALITY}

that person-activity fit is instrumental to the success of interventions (Lyubomirsky \& Layous, 2013), researchers could even specifically recruit people who are already motivated to become more helpful. Participants could be led to select gender-inconsistent behaviors and be encouraged to make a plan for carrying out those helping behaviors in the following week. This plan might draw on implementation intentions to connect the behavior to a situational context (e.g., "when I go to the grocery store, then I will help someone carry their bags to their car"; Gollwitzer, 1993); the purpose of this self-regulatory technique is to internalize this "when...then" (or "if...then") contingency, so that the situation triggers the behavior without much thought. Successful mastery of several gender-inconsistent tasks should result in people realizing that they are more capable of gender-inconsistent helping than they previously thought

- via the process of self-perception, observing one's own behavior can inform subsequent selfrelevant cognitions (Bem, 1972).

Although we believe that people are already more capable than they know, these interventions could be enhanced by first teaching people prosocial skills (see Table 1 Intervention 6). This could be done under the guise of a life skills workshop, wherein participants undertake resourcefulness training and learn a new way of helping every day, from providing emotional comfort to those distress to providing moderate physical assistance. This kind of prosocial skills training will empower people to feel motivated to approach, rather than avoid, providing help regardless of the masculinity or femininity of the context. The same life skills training workshops could be scaled and offered to adults as well as children (in schools or through continuing education courses). A developmental research trajectory would be useful to help uncover ways to undermine the early internalization of gender role stereotypes around helping. Through early exposure to many forms of prosocial behavior in a safe and friendly 


\section{HELPING TO PROMOTE GENDER EQUALITY}

environment, children will begin to develop stronger helping self-efficacy earlier in life.

Longitudinal research will, of course, be needed to truly document the sustained impact of such training studies, but other work has shown evidence of the immediate impact of similar types of interventions among children (e.g., Schonert-Reichl et al., 2015).

The above interventions might be strengthened by encouraging open, growth-oriented mindsets in helpers. Research on mindsets illustrates the impact of people's perceptions of their ability to learn and develop new skills. School-aged children who have growth mindsets, and view intelligence as malleable, are more likely to form and work toward goals associated with learning new concepts. Conversely, students who have fixed mindsets, and view intelligence as innate and unchangeable, tend to pursue fewer goals related to learning new skills, but rather work toward engaging in actions that document or illustrate their intelligence (Blackwell, Trzesniewski, \& Dweck, 2007; Dweck, 1999; 2008; 2017). When faced with difficult or unfamiliar tasks, growth mindsets have been shown to be most effective for success and goal achievement because people will view this as an opportunity to increase learning, resulting in decreased anxiety, and increased effort, performance, and task engagement (Dweck, 1999; Yeager et al., 2016; Yeager \& Dweck, 2012). Therefore, putting potential helpers in a more open, growth-oriented mindset could reduce the likelihood that they react defensively when learning skills that are not in line with their traditional gender roles. The mindset manipulation could also serve to improve helping self-efficacy, in a broad sense, because helpers will be more likely to endorse the idea that they have the capacity to figure out ways of helping, even if a situation is unfamiliar. We note that although there is a large body of work supporting the utility of individual growth mindsets, researchers have recently called the strength of this evidence into question (Burgoyne, Hambrick, \& Macnamara, 2020). Examining the utility of growth mindsets 


\section{HELPING TO PROMOTE GENDER EQUALITY}

as we suggest here would provide an opportunity for further testing of growth mindset models in a novel context.

In sum, self-efficacy for gender-inconsistent helping could be cultivated through educational interventions, to empower people to help by making them realize they have the capacity, even if they assume they do not. These kinds of interventions might also be enriched by pairing them with growth mindset manipulations or reinforcing a sense of success about their helping behavior.

\section{Synergistic interventions}

The specific interventions we propose above each target one factor of the GRIP model (see Figure 1, interventions would target Paths B, C, \& D simultaneously), but could also be combined to provide a more powerful catalyst for change. Consistent with the TPB (Ajzen, 2011), we expect that the three key proximal factors (attitudes, subjective norms, and selfefficacy) function as interdependent predictors of behavioral intentions and also influence one another. Given the interdependence of these psychological mechanisms, we reason that multipronged intervention approaches targeting more than one factor simultaneously are likely to be even more effective at encouraging gender-inconsistent helping. For example, efforts to shift focus away from the self to reduce negative (and induce positive) attitudes could be further enhanced by informing helpers about the relaxed social norms related to gender role violations in the context of helping. Additionally, assuaging people's fears about being negatively perceived for helping in a gender-inconsistent way could also affect the process by which gender stereotypes are internalized into the self-concept, thereby boosting one's positive attitudes along with their confidence about their own abilities to help (i.e., self-efficacy would be less restricted by the influence of social norms). Thus, a fruitful avenue for additional research is to consider 


\section{HELPING TO PROMOTE GENDER EQUALITY}

new ways to combine and integrate interventions so that they can affect multiple psychological pathways in the GRIP model simultaneously. Doing so is likely to increase the effectiveness and potency of each hypothesized intervention.

Even when a single intervention is used, it may effect change on multiple pathways. For instance, an intervention focused on shifting perceptions of the subjective norms around genderinconsistent helping could also result in more positive attitudes. Similarly, an intervention focused on increasing self-efficacy by having people carry out multiple gender-inconsistent helping tasks is also likely to result in more positive attitudes because when people help others, they feel a sense of perceived impact (self-efficacy), which makes them feel good about helping. Upon having a positive helping experience, people should update their prior attitudes and expectations about the rewards of helping in light of their new, first-hand information. This may be especially true for gender-inconsistent helping because people most likely start with very low expectations about their ability to help in a meaningful way. But, should they see that they were successful (via gratitude, praise, or simple task completion), they should feel greater efficacy and presumably anticipate more positive outcomes next time. For a brief summary of the proximal interventions we have proposed here, see Table 1.

\section{Initiating these interventions and making them stick}

Many actions, even if, or perhaps, particularly if, implicitly controlled by processes such as stereotype activation and habit cueing (Orbell \& Verplanken, 2010), require conscious deliberation and self-regulation if they are to be changed. Interventions to 'loosen the GRIP' are likely to benefit from utilizing naturally occurring opportunities that disrupt existing habits. These 'habit discontinuities' (Verplanken, Walker, Davis \& Jurasek, 2008; Verplanken and Wood, 2006: Verplanken, Roy \& Whitmarsh, 2018) provide a window of opportunity because 


\section{HELPING TO PROMOTE GENDER EQUALITY}

previous habits and behavioural tendencies are temporarily 'unfrozen'. Habitized behavior is characterized by unthinking repetition of past actions, such as the commute to work or school and, importantly, is accompanied by 'tunnel vision', a mindset in which the individual is almost immune to new information or alternative options (Aarts, Verplanken, \& van Knippenberg, 1997). When a habit is unblocked or suspended due to a change of context the person has to search out new information or advice and be open to alternative options. This is the basis of the Habit Discontinuity Hypothesis that predicts that deliberative interventions that capitalize on moments of change will be more effective than interventions delivered in stable contexts (Verplanken et al., 2018).

The interventions described above are intended to shift attitudes, perception of the norms, or self-efficacy, which should, in turn, affect individual people's intentions and actual helping behavior. The goal of these sorts of lab studies is to compare the effectiveness of different interventions, so that this knowledge can be harnessed to bring about lasting societal change. The next step in the process, then, is to address public awareness of this issue in an effort to garner greater interest and support for action. We reason that reaching large swaths of people (and, ideally, children) via normative messaging campaigns and existing programming is the best way to start a conversation and initiate the sort of social movement that will be necessary to effect change real over time.

Given that infants as young as 9 months exhibit gendered behaviors and preferences (Martin \& Ruble, 2004), it makes sense to implement efforts to undermine gender stereotypes as early in life as possible. Schools already incorporate elements of character education and personal development into their curricula. For example, the U.K. government provides a character education framework that supports schools "as they consider...the social, moral, 


\section{HELPING TO PROMOTE GENDER EQUALITY}

cultural and spiritual development of pupils" (Gov.UK, 2019). When addressing the question "How well do we promote the value of volunteering and service to others?", schools might consider teaching children about the variety of ways that people can be helpful, and provide opportunities for all kids to get experience helping in ways that are gender-inconsistent. Existing school-based programs designed to foster empathy, prosocial character and prosocial practice (e.g., https://rootsofempathy.org, https://www.randomactsofkindness.org) can also reflect a range of helping behaviors, and encourage children to practice a variety of familiar and novel forms. Scholarly research on growth mindset has education programs (e.g., https://www.mindsetworks.com/science/), and, importantly, organizations to help ensure that the latest research reaches education stakeholders (https://mindsetscholarsnetwork.org). These programs could easily be adapted to include gender-inconsistent helping tasks as exercises to facilitate kids' development of growth mindsets; indeed such programs might be ideal because they are perceived as challenging, but, in addition to the rewards of accomplishing a challenging task, helping brings its own rewards.

Another potential route to effect large-scale change is through role modelling. Research shows that a lack of female role models discourages girls from pursuing STEM subjects, and that the availability of role models can increase girls' interest and sense of belonging in STEM (e.g., Asgari et al., 2010; Stout et al., 2011). In terms of gender-inconsistent helping, movies and television could provide an accessible and robust source of modelling, with a powerfully wide reach. Television shows with openly gay characters, or characters with mental illnesses have been effective at reducing prejudice through the parasocial relationships that viewers build with those characters. Movies like Wonder Woman and Captain Marvel should, similarly, help establish the normality of women helping in stereotypically masculine ways. Television shows 


\section{HELPING TO PROMOTE GENDER EQUALITY}

like Sex Education, in which teenaged Otis provides not only instrumental but also emotional support to his classmates, help establish norms of men helping in stereotypically feminine ways.

When it comes to increasing adults' awareness of the issue, corporations could also promote gender-inconsistent helping. Companies are increasingly recognizing that investing in the wellness of their employees pays off, in terms of increased retention, fewer lost work days, and in the U.S., lower health care costs (Berry, Mirabito, \& Baun, 2010). This has resulted in a proliferation of corporate wellness companies that could add messaging around genderinconsistent helping into their toolkits. Indeed, prosocial behavior has been shown to increase team performance; pharmaceutical salespeople who were given a bonus to spend on their colleagues showed an improvement in performance (and a return on the company's investment in the cost of the bonus), whereas those who were given a bonus to spend on themselves did not. By including gender-inconsistent prosocial behavior in their toolkit of services, corporate wellness companies can help their clients improve wellness and performance, while simultaneously breaking down gender stereotypes. In sum, these real-world catalysts for change might be critically important for enhancing public interest in gender-inconsistent helping and laying the foundations upon which broader shifts in gender stereotypes can ultimately be built.

\section{Increasing gender-inconsistent helping at the distal level}

Having presented interventions to target the three proximal pathways in the GRIP model, we describe how changes to attitudes toward the behavior, subjective norms, and self-efficacy could feed back to inform the distal factors in the GRIP model (i.e., gender stereotypes about helping and gender stereotypes, more broadly; see Figure 1, Paths G \& H). First, we present an in-depth consideration of the types of changes in behavior that should be most effective at fostering gender equality within helping. Next, we revisit Social Role Theory (Eagly \& Wood, 


\section{HELPING TO PROMOTE GENDER EQUALITY}

2012) to discuss the specific processes through which gender-inconsistent helping might become simply "helping," which could subsequently spark macro-level changes in stereotypes and gender role expectations. We conclude by presenting three potential reasons for why loosening the grip of gender stereotypes on prosociality could lead to macro-level changes in the nature of gender stereotypes: (1) increased status and value of communal roles and traits; (2) strengthened associations between women and agency, and between men and communion; and (3) decreased occupational segregation.

We suggest that, over time, repeated instances of gender-inconsistent helping are likely to help reinforce positive attitudes towards, undermine false subjective norms about, and provide a stronger sense of self-efficacy around helping, for helpers and observers alike. Taking the perspective of someone observing changes in helping behavior, it is important to consider whether observing multiple people helping in a single gender-inconsistent way would have a different impact than observing a single person helping in multiple gender-inconsistent ways. The GRIP model supports the idea that both of these forms of repeated instances could serve to

interrupt the cycle of gendered helping, but this remains an open question. To our knowledge, all of the research reviewed above on perceptions of helpers is based on single instances of behavior, and perceivers are asked to make ratings of helpers based on this decontextualized information. It stands to reason, though, that repeated instances of gender-inconsistent helping might be more effective at shifting norms when multiple people are engaged in the focal behavior, relative to seeing a few people helping many times, due to the attributions people are likely to make for a helper's behavior. If a single helper engages in repeated instances of genderinconsistent helping, perceivers might make an internal attribution about that person, rather than infer that social norms are changing. For example, if a heterosexual man repeatedly provides 


\section{HELPING TO PROMOTE GENDER EQUALITY}

emotional support, the recipient may make an internal attribution and infer that he is a caring (though perhaps less masculine) person. It is unlikely, however, that the recipient of help will expect similar emotional support from other men (i.e., will not generalize these expectations to other men). We tend to take a more optimistic view, however, because repeated instances of gender-inconsistent helping at both the individual and societal levels are necessary to begin breaking down gender stereotypes related to helping.

Another caveat to this process is the potential for subtyping gender-inconsistent helpers viewing them as exceptions to the rule, rather than exemplars who represent shifting gender norms (e.g., "refencing"; Allport, 1954). Past research points to the importance of both the typicality of group members and the moderate extremity of counter-stereotypic behavior for promoting versus preventing stereotype change (e.g., McIntyre, Paolini, \& Hewstone, 2016; Richards \& Hewstone, 2001). Building on this work, we reason that gender-inconsistent helping should be most effective at ultimately leading to broader change in gender stereotypes when helping is enacted by men and women who are otherwise gender typical (i.e., look and act in ways that are culturally normative for their gender category), and when the behavior is a moderate stereotype violation (i.e., the innocuous kinds of everyday helping behaviors the GRIP model highlights, rather than extreme or heroic kinds of helping). Future research will need to test these open questions and caveats.

Setting aside the nuances of societal- versus individual-level repeated instances of gender-inconsistent helping, once targeted interventions are conducted to address the attitudes, subjective norms, and self-efficacy associated with gendered helping and, as a result, individual helping behavior begins to change, the macro processes outlined by SRT (Eagly \& Wood, 2012) again become the focus of the GRIP model. Specifically, as men and women begin adopting new 


\section{HELPING TO PROMOTE GENDER EQUALITY}

helping roles, this novel role adoption will inform the content of gender stereotypes more broadly (see Figure 1 Path H). Repeated observations of men and women in these new helping roles will lead to changes in gender-based expectations (i.e., stereotypes), and eventually changes in behavior across society more broadly. Given these processes, the content of attitudes, subjective norms, and self-efficacy are also informed through the internalization of gendered beliefs and identities, but the cycle does not end at this point.

The GRIP model posits that, in line with SRT (Eagly \& Wood, 2012), gendered beliefs and identities are recursively informed by the content of attitudes, subjective norms, and selfefficacy via behavior (Figure 1 Paths G \& H). This means that as helping-related roles become less differentiated by gender, stereotypes about the characteristics necessary to engage in different forms of helping will also change. These changed stereotypes will then become internalized, leading to change in individual attitudes, subjective norms, and self-efficacy. Finally, if the (positive) experiences predicted by the GRIP model are cultivated through gender role violations in the context of helping, this has the potential to increase people's comfort with testing out role violations in other contexts. Simply put, once gender-inconsistent helping is just "helping," perhaps it will become more typical for people to experiment with venturing outside of gender boundaries in other ways. This role flexibility then has the potential to inform and revise the content of gender stereotypes in a more general sense. There are three theoretical reasons why this might happen.

First, promoting gender-inconsistent helping could change cultural gender stereotypes by increasing the status and value of communal roles and traits. According to the GRIP model, gendered helping reinforces gender stereotypes across time and situations because people continue to infer that men and women have particular skillsets that are necessary to perform 


\section{HELPING TO PROMOTE GENDER EQUALITY}

particular helping behaviors. The reinforcement of these stereotypes also serves to maintain the existing hierarchy favoring men as higher status. Specifically, to the degree that people believe women have stronger socioemotional skills than men, they will continue to place an unfair burden on women to sacrifice more of their own time and resources to help others, leaving less time for other pursuits (e.g., career advancement, personal hobbies, etc.; Parkner, 2015; Pew Research Center, 2015). But, in line with Status Value Theory (Ridgeway \& Correll, 2004), if more men were willing to take on communal forms of helping, then communal forms of helping would increase in status. Empirical evidence supports this idea, showing that both men and women assign greater value to domains associated with men and devalue domains associated with women (Schmader, Major, Eccleston, \& McCoy, 2001). Given this line of reasoning, it is also possible that increasing the proportion of women performing agentic forms of helping could lead to a decrease in the perceived value of those helping behaviors. Therefore, we reason that if there were an equal proportion of men and women doing both agentic and communal helping behaviors, rather than reversing the gender proportions for who does what type of helping, then the characteristics associated with each type of helping would no longer be differentially tied to gender categories (see SRT; Eagly \& Wood, 2012).

Second, increasing gender-inconsistent helping could dismantle broader gender stereotypes by strengthening the cognitive associations between women and agency as well as men and communion. Consistent with SRT and the GRIP model (see Figure 1), if agentic and communal helping behaviors are no longer differentially performed by men and women, the stereotypic assumption that people do not have the necessary skills to do gender-inconsistent helping will be diluted. The underlying rationale for this point is supported by classic research on the fundamental attribution error (FAE; Jones \& Harris, 1967; Ross, Amabile, \& Steinmetz, 


\section{HELPING TO PROMOTE GENDER EQUALITY}

1977). In line with the original FAE theorizing, people often attribute an actor's behavior to internal, dispositional factors while discounting or downplaying the impact of external factors stemming from the social situation, especially when they believe the actor performed the behavior by choice. In this case, the more women are seen doing agentic forms of helping, especially those that involve fixing things or solving problems, the more competent observers will perceive them to be. Similarly, when men are seen doing more communal forms of helping, such as supporting and comforting others, the more caring observers will perceive them to be. And as women are viewed through the lens of competence and men through the lens of care, it increases the likelihood that they will be encouraged and feel empowered to adopt more counterstereotypic roles, thereby promoting gender equality and contributing to the sociocultural process of undermining traditional gender role stereotypes as articulated by SRT (Eagly, 1987; Eagly \& Wood, 2012).

Third, building on the previous two points, increasing gender-inconsistent helping has the potential to temper broader gender role stereotypes by decreasing occupational segregation, particularly in prosocially-oriented jobs. Research indicates that a primary reason for the slowed rate of change in gender stereotypes regarding agency and communion is the persistence of occupational gender segregation (see Eagly et al., 2020). The propensity for and perpetuation of gendered helping may contribute to the systematic under-representation of men and women in certain careers. For example, gender stereotypes about helping may prevent men from entering careers in nursing, social work, and education, whereas parallel gender stereotypes might prevent women from adopting jobs in law enforcement, firefighting, or even surgery, which involves higher risk than practicing general medicine. Understanding how gender stereotypes restrict helping behavior, then, has implications for addressing these patterns of systematic gender 


\section{HELPING TO PROMOTE GENDER EQUALITY}

under-representation. And, as the GRIP model suggests (see Figure 1), once more men and women adopt roles that do not follow traditional gender stereotypes, that will influence the content of those gender stereotypes, which will then seep into individual-level behaviors by shifting internalized attitudes, subjective norms, and self-efficacy accordingly. It is in this way that the cycle of gender stereotyping on a broad societal-level impacts and is impacted by individual-level gendered helping behavior.

\section{Concluding Remarks}

In this paper, we argue that challenging gender role stereotypes about helping could bring society one step closer toward achieving gender equality. We propose an integrative process model (the GRIP model; Figure 1) to explain how distal and proximal factors lead to gender differences in the kinds of help men and women provide. We argue that prosociality provides a unique entry point for effecting change because helping others is immediately rewarding, morally valued by society for both men and women, and is unlikely to violate the gender status hierarchy, which makes it less susceptible to the negative outcomes of traditional gender role stereotype violations. Moreover, the GRIP model suggests interventions to target the proximal barriers to gender-inconsistent helping which may interrupt the larger cycle of stereotype maintenance. Ultimately, changes in cultural stereotypes at the distal level could be triggered through a feedback loop that loosens gender role restrictions on behavior (both prosocial and otherwise). This work has implications for promoting gender equality by raising the status of communal behaviors and fostering a more equal division of labor between men and women. 


\section{HELPING TO PROMOTE GENDER EQUALITY}

\section{References}

Aarts, H., Verplanken, B. van Knippenberg, A. (1997). Habit and information use in travel mode choices. Acta Psychologica, 96, 1-14. doi: 10.1016/S0001-6918(97)00008-5

Abraham, C., \& Sheeran, P. (2003). Acting on intentions: The role of anticipated regret. British Journal of Social Psychology, 42, 495-511. doi:10.1348/014466603322595248

Abraham, C., \& Sheeran, P. (2004). Deciding to exercise: The role of anticipated regret. British Journal of Health Psychology, 9, 269-278. doi: 10.1348/135910704773891096

Ajzen, I. (1991). The theory of planned behavior. Organizational Behavior and Human Decision Processes, 50, 179-211. doi: 10.4135/9781446249215.n22

Ajzen, I. (2002). Perceived behavioral control, self-efficacy, locus of control, and the theory of planned behavior. Journal of Applied Social Psychology, 32(4), 665-683.

Ajzen, I. (2011). The theory of planned behaviour: Reactions and reflections. Psychology and Health, 26(9), 1113-1127. doi: 10.1080/08870446.2011.613995

Aknin, L. B., Broesch, T., Hamlin, J. K., \& Van de Vondervoort, J. W. (2015). Prosocial behavior leads to happiness in a small-scale rural society. Journal of Experimental Psychology: General, 144(4), 788-795. doi:10.1037/xge0000082

Aknin, L.B., Barrington-Leigh, C. P., Dunn, E. W., Helliwell, J. F., Burns, J., Biswas-Diener, R., ... Norton, M. I. (2013). Prosocial spending and well-being: Cross-cultural evidence for a psychological universal. Journal of Personality and Social Psychology, 104(4), 635-652.

Aknin, L. B., Dunn, E. W., \& Norton, M. I. (2012). Happiness runs in a circular motion: Evidence for a positive feedback loop between prosocial spending and happiness. Journal 


\section{HELPING TO PROMOTE GENDER EQUALITY}

of Happiness Studies, 13(2), 347-355. doi: 10.1007/s10902-011-9267-5

Aknin, L. B., Dunn, E. W., Proulx, J., Lok, I., \& Norton, M. I. (2020). Does spending money on others promote happiness?: A registered replication report. Journal of Personality and Social Psychology. Advance online publication. https://doi.org/10.1037/pspa0000191

Allen, J., \& Smith, J. L. (2011). The influence of sexuality stereotypes on men's experience of gender-role incongruence. Psychology of Men \& Masculinity, 12, 77-96. doi:10.1037/a0019678

Allport, F. H. (1924). Social Psychology. Boston: Houghton Mifflin.

Allport, G. W. (1954). The nature of prejudice. Reading, MA: Addison-Wesley.

Andreoni, J. (1990). Impure altruism and donations to public goods: A theory of warm-glow giving. Economic Journal, 100, 464-477. doi: 10.2307/2234133

Anik, L., Aknin, L. B., Norton, M. I., Dunn, E. W., \& Quoidbach, J. (2013). Prosocial bonuses increase employee satisfaction and team performance. PloS one, 8(9), e75509.

Asgari, S., Dasgupta, N., \& Cote, N. G. (2010). When does contact with successful ingroup members change self-stereotypes? A longitudinal study comparing the effect of quantity vs. quality of contact with successful individuals. Social Psychology, 41(3), 203-211. doi: $10.1027 / 1864-9335 / \mathrm{a} 000028$

Baron, A. S., Schmader, T., Cvencek, D., \& Meltzoff, A. N. (2014). The gendered self-concept: How implicit gender stereotypes and attitudes shape self-definition. In P. J. Leman \& H. R. Tenenbaum (Eds.), Gender and development (pp. 109-132). East Sussex: Psychology Press. doi: $10.4324 / 9781315870878$ 


\section{HELPING TO PROMOTE GENDER EQUALITY}

Baumeister, R. F., DeWall, C. N., Vohs, K. D., \& Alquist, J. L. (2010). Does emotion cause behavior (apart from making people do stupid, destructive things)? In R. Agnew, Christpher, E. Carlston, Donal, G. Graziano, William, \& R. Kelly, Janice (Eds.), Then a miracle occurs: Focusing on behavior in social psychological theory and research. Oxford University Press.

Baumeister, R. F., \& Leary, M. R. (1995). The need to belong: desire for interpersonal attachments as a fundamental human motivation. Psychological Bulletin, 117(3), 497-529.

Baumeister, R. F., Vohs, K. D., DeWall, C. N., \& Zhang, L. (2007). How emotion shapes behavior: Feedback, anticipation, and reflection, rather than direct causation. Personality and Social Psychology Review, 11(2), 167-203. doi: 10.1177/1088868307301033

Becker, S. W., \& Eagly, A. H. (2004). The heroism of women and men. American Psychologist, 59(3), 163-178. doi: 10.1037/0003-066X.59.3.163

Bem, D. J. (1972). Self-perception theory. Advances in experimental social psychology, 6(1), 162.

Berry, L., Mirabito, A. M., \& Baun, W. (2010). What's the hard return on employee wellness programs?. Harvard business review, December, 2012-68.

Biernat, M., \& Manis, M. (1994). Shifting standards and stereotype-based judgments. Journal of Personality and Social Psychology, 66(1), 5-20. doi: 10.1037/0022-3514.66.1.5

Blackwell, L. S., Trzesniewski, K. H., \& Dweck, C. S. (2007). Implicit theories of intelligence predict achievement. Child Development, 78(1), 246-263. doi: 0009-3920/2007/7801-0014

Block, K., Croft, A., De Souza, L., Schmader, T. (2019). Do people care if men don't care about 


\section{HELPING TO PROMOTE GENDER EQUALITY}

caring? The asymmetry in support for changing gender roles. Journal of Experimental Social Psychology, 83, 112-131.

Block, K., Croft, A., \& Schmader, T. (2018). Worth less?: Why men (and women) devalue careoriented careers. Frontiers in Psychology, 9, 1353. https://doi.org/10.3389/fpsyg.2018.01353

Block, K., Gonzalez, A. M., Schmader, T., \& Baron, A. S. (2018). Early gender differences in core values predict anticipated family versus career orientation. Psychological Science, 29(9), 1540-1547. doi: 10.1177/0956797618776942

Bohns, V. K. (2016). (Mis) Understanding our influence over others: A review of the underestimation-of-compliance effect. Current Directions in Psychological Science, 25, 119-123.

Borgonovi, F. (2008). Doing well by doing good. The relationship between formal volunteering and self-reported health and happiness. Social Science and Medicine, 66, 2321-2334. doi: 10.1016/j.socscimed.2008.01.011

Bosson, J. K., Haymovitz, E. L., \& Pinel, E. C. (2004). When saying and doing diverge: The effects of stereotype threat on self-reported versus non-verbal anxiety. Journal of Experimental Social Psychology, 40, 247-255. doi:10.1016/S0022- 1031(03)00099-4

Bosson, J. K., Prewitt-Freilino, J. L., \& Taylor, J. N. (2005). Role rigidity: A problem of identity misclassification? Journal of Personality and Social Psychology, 89(4), 552-565. doi: $10.1037 / 0022-3514.89 .4 .552$

Bosson, J. K., Taylor, J. N., \& Prewitt-Freilino, J. L. (2006). Gender role violations and identity 


\section{HELPING TO PROMOTE GENDER EQUALITY}

misclassification: The roles of audience and actor variables. Sex Roles, 55(1-2), 13-24. doi: $10.1007 / \mathrm{s} 11199-006-9056-5$

Bosson, J. K., \& Vandello, J. A. (2011). Precarious manhood and its links to action and aggression. Current Directions in Psychological Science, 20(2), 82-86. doi: $10.1177 / 0963721411402669$

Brescoll, V. L., Dawson, E., \& Uhlmann, E. L. (2010). Hard won and easily lost: The fragile status of leaders in gender-stereotype-incongruent occupations. Psychological Science, 21(11), 1640-1642. doi: 10.1177/0956797610384744

Brescoll, V. L., \& Uhlmann, E. L. (2008). Can an angry woman get ahead? Status conferral, gender, and expression of emotion in the workplace. Psychological Science, 19(3), 268275.

Brown, E. R., \& Diekman, A. B. (2010). What will I be? Exploring gender differences in near and distant possible selves. Sex Roles, 63, 568-579. doi: 10.1007/s11199-010-9827-x

Burgoyne, A. P., Hambrick, D. Z., \& Macnamara, B. N. (2020). How firm are the foundations of mind-set theory? The claims appear stronger than the evidence. Psychological Science, 31(3), 258-267.

Burleson, B. R., \& Kunkel, A. W. (2006). Revisiting the different cultures thesis: An assessment of sex differences and similarities in supportive communication. In K. Dindia \& D. J. Canary (Eds.), Sex differences and similarities in communication (2nd ed., pp. 137-159). Mahwah, NJ: Lawrence Erlbaum Associates Publishers.

Byron, K., \& Post, C. (2016). Women on boards of directors and corporate social performance: 


\section{HELPING TO PROMOTE GENDER EQUALITY}

A meta-analysis. Corporate Governance: An International Review, 24(4), 428-442.

Cancian, F. M., \& Oliker, S. J. (2000). Caring and gender. Thousand Oaks, CA: Pine Forge Press.

Carlsmith, K. M., Wilson, T. D., \& Gilbert, D. T. (2008). The paradoxical consequences of revenge. Journal of Personality and Social Psychology, 95(6), 1316-1324. doi: $10.1037 / \mathrm{a} 0012165$

Ceci, S. J., \& Williams, W. M. (2011). Understanding current causes of women's underrepresentation in science. Proceedings of the National Academy of Sciences of the United States of America, 108, 3157-3162. doi:10.1073/pnas.1014871108

Chaiken, S., \& Trope, Y. (Eds.). (1999). Dual-process theories in social psychology. Guilford Press.

Cialdini, R. B., Darby, B. L., \& Vincent, J. E. (1973). Transgression and altruism: A case for hedonism. Journal of Experimental Social Psychology,9, 502-516. doi:10.1016/00221031(73)90031-0

Cialdini, R.B., Kallgren, C.A., \& Reno, R.R. (1990). A focus theory of normative conduct: A theoretical refinement and re-evaluation of the role of norms in human behaviors. Journal of Personality and Social Psychology, 58, 1015-1026.

Cramer, D. (2006). How a supportive partner may increase relationship satisfaction. British journal of guidance \& counselling, 34(1), 117-131.

Croft, A., Schmader, T., \& Block, K. (2015). An underexamined inequality: Cultural and psychological barriers to men's engagement with communal roles. Personality and Social 


\section{HELPING TO PROMOTE GENDER EQUALITY}

Psychology Review, 19(4), 343-370. doi: 10.1177/1088868314564789

Croft, A., Schmader, T., \& Block, K. (2019). Life in the balance: Are women's possible selves constrained by men's domestic involvement? Personality and Social Psychology Bulletin, 1-16. doi: 10.1177/0146167218797294

Croft, A., Schmader, T., Block, K., \& Baron, A.S. (2014). The second shift reflected in the second generation: Do parents' gender roles at home predict children's aspirations? Psychological Science, 25, 1418-1428. doi: 10.1177/0956797614533968

Crosby, J. R., King, M., \& Savitsky, K. (2014). The minority spotlight effect. Social Psychological and Personality Science, 5(7), 743-750. doi: 10.1177/1948550614527625

Cryder, C. E., Loewenstein, G., \& Scheines, R. (2013). The donor is in the details. Organizational Behavior and Human Decision Processes, 120(1), 15-23. doi: 10.1016/j.obhdp.2012.08.002

Curry, O. S., Rowland, L. A., Van Lissa, C. J., Zlotowitz, S., McAlaney, J., \& Whitehouse, H. (2018). Happy to help? A systematic review and meta-analysis of the effects of performing acts of kindness on the well-being of the actor. Journal of Experimental Social Psychology, 76, 320-329.

Diekman, A. B., \& Clark, E. K. (2015). Beyond the damsel in distress: Gender differences and similiarities in enacting prosocial behavior. In The Oxford Handbook of Prosocial Behavior (pp. 375-391). doi: 10.1093/oxfordhb/9780195399813.013.028

Diekman, A. B., \& Eagly, A. H. (2000). Stereotypes as dynamic constructs: Women and men of the past, present, and future. Personality and Social Psychology Bulletin, 26(10), 1171- 


\section{HELPING TO PROMOTE GENDER EQUALITY}

1188. doi: $10.1177 / 0146167200262001$

Diekman, A. B., \& Goodfriend, W. (2006). Rolling with the changes: A role congruity perspective on gender norms. Psychology of Women Quarterly, 30, 369-383.

Diener, E., \& Seligman, M. E. (2002). Very happy people. Psychological science, 13(1), 81-84.

Dovidio, J. F., \& Penner, L. A. (2001). Helping and altruism. In G. J. O. Fletcher \& M. S. Clark (Eds.), Blackwell handbook of social psychology: Interpersonal processes (pp. 162-195). Blackwell Publishers, Ltd. doi: 10.1111/b.9780631212294.2002.x

Dovidio, J. F., Piliavin., J. A., Gaertner, S. L., Schroeder., D. A., \& Clark, R. D. III. (1991). The arosual: Cost-reward model and the process of intervention: A review of the evidence. In M. S. Clark (Ed.), Review of personality and social psychology, Vol. 12. Prosocial behavior (pp. 86-118). Thousand Oaks, CA: Sage Publications, Inc.

Dunn, E. W., Aknin, L. B., \& Norton, M. I. (2008). Spending money on others promotes happiness. Science, 319(5870), 1687-1688. doi: 10.1126/science.1152864

Dunn, E. W., Biesanz, J. C., Human, L. J., \& Finn, S. (2007). Misunderstanding the affective consequences of everyday social interactions: The hidden benefits of putting one's best face forward. Journal of Personality and Social Psychology, 92(6), 990-1005. doi: 10.1037/0022-3514.92.6.990

Dweck, C. (2017). From needs to goals and representations: Foundations for a unified theory of motivation, personality, and development. Psychological Review, 124(6), 689-719. doi: $10.1037 / \mathrm{rev} 0000082$

Dweck, C. S. (2013). Self-Theories: Their role in motivation, achievement and development. 


\section{HELPING TO PROMOTE GENDER EQUALITY}

Psychology Press.

Dweck, C. S. (2008). Can personality be changed? The role of beliefs in personality and change. Current Directions in Psychological Science, 17(6), 391-394.

Dweck, C. S. (1999). Self-theories: Their role in motivation, personality, and development. Philadelphia, PA: Taylor \& Francis.

Eagly, A. H. (1987). Sex differences in social behavior: A social-role interpretation. Lawrence Erlbaum.

Eagly, A. H. (2009). The his and hers of prosocial behavior: An examination of the social psychology of gender. American Psychologist, 64(8), 644-658. doi: 10.1037/0003066X.64.8.644

Eagly, A. H. (2016). When passionate advocates meet research on diversity, does the honest broker stand a chance? Journal of Social Issues, 72(1), 199-222.

Eagly, A. H., \& Crowley, M. (1986). Gender and helping behavior: A meta-analytic review of the social psychological literature. Psychological Bulletin, 100(3), 283-308.

Eagly, A. H., Johannesen-Schmidt, M. C., \& van Engen, M. L. (2003). Transformational, transactional, and laissez-faire leadership styles: A meta-analysis comparing women and men. Psychological Bulletin, 129(4), 569-591. doi: 10.1037/0033-2909.129.4.569

Eagly, A. H., \& Karau, S. J. (2002). Role congruity theory of prejudice toward female leaders. Psychological Review, 109(3), 573-598. doi: 10.1037/0033-295X.109.3.573

Eagly, A. H., Nater, C., Miller, D. I., Kaufmann, M., \& Sczesny, S. (2020). Gender stereotypes have changed: A cross-temporal meta-analysis of U.S. public opinion polls from 1946 to 


\section{HELPING TO PROMOTE GENDER EQUALITY}

2018. American Psychologist, 75(3), 301-315. https://doi.org/10.1037/amp0000494

Eagly, A. H., \& Sczesny, S. (2009). Stereotypes about women, men, and leaders: Have times changed? In M. Barreto, M. K. Ryan, \& M. T. Schmitt (Eds.), Psychology of women book series. The glass ceiling in the 21st century: Understanding barriers to gender equality (pp. 21-47). Washington, D.C.: American Psychological Association.

Eagly, A. H., \& Steffen, V. J. (1984). Gender stereotypes stem from the distribution of women and men into social roles. Journal of Personality and Social Psychology, 46(4), 735.

Eagly, A. H., \& Wood, W. (2012). Social role theory. In P. van Lange, A. Kruglanski, \& E. T. Higgins (Eds.), Handbook of theories in social psychology (pp. 458-476). Thousand Oaks, CA: Sage Publications.

Eagly, A. H., Wood, W., \& Diekman, A. B. (2000). Social role theory of sex differences and similarities: A current appraisal. The Developmental Social Psychology of Gender, 12, 174.

Eaton, A. A., \& Rose, S. (2011). Has dating become more egalitarian? A 35 year review using sex roles. Sex Roles, 64, 843-862. doi: 10.1007/s11199-011-9957-9

England, P. (2010). The gender revolution. Gender \& Society, 24(2), 149-166. doi: $10.1177 / 0891243210361475$

England, P., Levine, A., \& Mishel, E. (2020). Progress toward gender equality in the United States has slowed or stalled. Proceedings of the National Academy of Sciences, 117(13), 6990-6997.

Epley, N., Keysar, B., Van Boven, L., \& Gilovich, T. (2004). Perspective taking as egocentric anchoring and adjustment. Journal of Personality and Social Psychology, 87(3), 327-339. 


\section{HELPING TO PROMOTE GENDER EQUALITY}

doi: 10.1037/0022-3514.87.3.327

Epley, N., Savitsky, K., \& Gilovich, T. (2002). Empathy neglect: Reconciling the spotlight effect and the correspondence bias. Journal of Personality and Social Psychology, 83(2), 300312. doi: $10.1037 / 0022-3514.83 .2 .300$

Epley, N., \& Schroeder, J. (2014). Mistakenly seeking solitude. Journal of Experimental Psychology: General, 143(5), 1980-1999. doi: 10.1037/a0037323

Farrell, S. K., \& Finkelstein, L. M. (2007). Organizational citizenship behavior and gender: Expectations and attributions for performance. North American Journal of Psychology, 9(1), 81-96.

Forbes, C. E., Schmader, T., \& Allen, J. J. B. (2008). The role of devaluing and discounting in performance monitoring: A neurophysiological study of minorities under threat. Social Cognitive and Affective Neuroscience, 3, 253-261. doi: 10.1093/scan/nsn012

Gilbert, D. T., Morewedge, C. K., Risen, J. L., \& Wilson, T. D. (2004). Looking forward to looking backward: The misprediction of regret. Psychological Science, 15(5), 346-350.

Gilovich, T., Kruger, J., \& Medvec, V. H. (2002). The spotlight effect revisited: Overestimating the manifest variability of our actions and appearance. Journal of Experimental Social Psychology, 38, 93-99. doi: 10.1006/jesp.2001.1490

Gilovich, T., Medvec, V. H., \& Savitsky, K. (2000). The spotlight effect in social judgment: An egocentric bias in estimates of the salience of one's own actions and appearance. Journal of Personality and Social Psychology, 78(2), 211-222. doi: 10.1037/0022-3514.78.2.211

Gilovich, T., \& Savitsky, K. (1999). The spotlight effect and the illusion of transparency: 


\section{HELPING TO PROMOTE GENDER EQUALITY}

Egocentric assessments of how we are seen by others. Current Directions in Psychological Science, 8(6), 165-168.

Gollwitzer, P. M. (1993). Goal achievement: The role of intentions. European Review of Social Psychology, 4(1), 141-185.

Gov.UK (2019, November 5). Character education framework: Non-statutory guidance to schools on character education and development for pupils.

https://www.gov.uk/government/publications/character-education-framework

Grandey, A. A., \& Gabriel, A. S. (2015). Emotional labor at a crossroads: Where do we go from here?. Annual Review of Organizational Psychology and Organizational Behavior, 2(1), 323-349.

Grant, A. M. (2012). Leading with meaning: Beneficiary contact, prosocial impact, and the performance effects of transformational leadership. Academy of Management Journal, $55(2), 458-476$.

Grant, A. M., \& Gino, F. (2010). A little thanks goes a long way: Explaining why gratitude expressions motivate prosocial behavior. Journal of Personality and Social Psychology, 98(6), 946-955. doi: 10.1037/a0017935

Gross, J. J. \& John, O. P. (2003). Individual differences in two emotion regulation processes: Implications for affect, relationships, and well-being. Journal of Personality and Social Psychology, 85(2), 348-362

Haines, E. L., Deaux, K., \& Lofaro, N. (2016). The times they are a-changing ... or are they not? A comparison of gender stereotypes, 1983-2014. Psychology of Women Quarterly, 40(3), 


\section{HELPING TO PROMOTE GENDER EQUALITY}

353-363. doi: 10.1177/0361684316634081

Haski-Leventhal, D. (2009). Elderly volunteering and well-being: A cross-European comparison based on SHARE data. Voluntas, 20, 388-404. doi: 10.1007/s11266-009-9096-x

Heilman, M. E., \& Chen, J. J. (2005). Same behavior, different consequences: Reactions to men's and women's altruistic citizenship behavior. Journal of Applied Psychology, 90(3), 431-441. doi: 10.1037/0021-9010.90.3.431

Heilman, M. E., \& Wallen, A. S. (2010). Wimpy and undeserving of respect: Penalties for men's gender-inconsistent success. Journal of Experimental Social Psychology, 46(4), 664-667. doi: 10.1016/j.jesp.2010.01.008

Helliwell, J. F., Huang, H., \& Wang, S. (2019). Changing world happiness. World Happiness Report 2019.

Hoffner, C. A., \& Cohen, E. L. (2015). Portrayal of mental illness on the TV series Monk: Presumed influence and consequences of exposure. Health Communication, 30(10), 10461054.

Horowitz, J. M. (2015, November 5). Who does more at home when both parents work? Depends on which one you ask. Pew Research Center: Fact Tank News in the Numbers. https://www.pewresearch.org/fact-tank/2015/11/05/who-does-more-at-home-when-bothparents-work-depends-on-which-one-you-ask/

Hyde, J. S. (2005). The gender similarities hypothesis. American Psychologist, 60(6), 581-592. doi: 10.1037/0003-066X.60.6.581

Ickes, W., Gesn, P. R., \& Graham, T. (2000). Gender differences in empathic accuracy: 


\section{HELPING TO PROMOTE GENDER EQUALITY}

Differential ability or differential motivation? Personal Relationships, 7, 95-109. doi:10.1111/j.1475-6811.2000.tb00006.x

Jamieson, J. P., \& Harkins, S. G. (2007). Mere effort and stereotype threat performance effects. Journal of Personality and Social Psychology, 93(4), 544-564. doi: 10.1037/00223514.93.4.544

Jeong, M., Minson, J. A., \& Gino, F. (2020). In Generous Offers I Trust: The Effect of FirstOffer Value on Economically Vulnerable Behaviors. Psychological Science, advance online publication. doi: 0956797620916705.

Jones, E. E. \& Harris V. A. (1967). The attribution of attitudes. Journal of Experimental Social Psychology, 3, 1-24.

Kahneman, D. (2011). Thinking, fast and slow. Macmillan.

Kidder, D. L. (2002). The influence of gender on the performance of organizational citizenship behaviors. Journal of Management, 28(5), 629-648.

Klein, N., Grossmann, I., Uskul, A. K., Kraus, A. A., \& Epley, N. (2015). It pays to be nice, but not really nice: Asymmetric reputations from prosociality across 7 countries. Judgment and Decision Making, 10(4), 355-364.

Koenig, A., \& Eagly, A. (2005). Stereotype threat in men on a test of social sensitivity. Sex Roles, 52, 489-496. doi:10.1007/ s11199-005-3714-x

Konrath, S., Fuhrel-Forbis, A., Lou, A., \& Brown, S. (2012). Motives for volunteering are associated with mortality risk in older adults. Health Psychology, 31(1), 87.

Koo, M., Algoe, S. B., Wilson, T. D., \& Gilbert, D. T. (2008). It's a wonderful life: Mentally 


\section{HELPING TO PROMOTE GENDER EQUALITY}

subtracting positive events improves people's affective states, contrary to their affective forecasts. Journal of Personality and Social Psychology, 95(5), 1217-1224. doi: $10.1037 / \mathrm{a} 0013316$

Lamy, L., Fischer-Lokou, J., \& Guéguen, N. (2009). Induced reminiscence of love and chivalrous helping. Current Psychology, 28(3), 202-209. doi: 10.1007/s12144-009-9059-9

Latane, B., \& Darley, J. M. (1970). The unresponsive bystander: Why doesn't he help? New York, NY: Appleton-Century Crofts.

Leyens, J., Desert, M., Croizet, J., \& Darcis, C. (2000). Stereotype threat: Are lower status and history of stigmatization preconditions of stereotype threat? Personality and Social Psychology Bulletin, 26, 1189-1199.

Low, R. S., Overall, N. C., Hammond, M. D., \& Girme, Y. U. (2017). Emotional suppression during personal goal pursuit impedes goal strivings and achievement. Emotion, 17(2), 208.

Lyubomirsky, S., \& Layous, K. (2013). How do simple positive activities increase well-being?. Current directions in Psychological Science, 22(1), 57-62.

Lyubomksky, S., Sheldon, K. M., \& Schkade, D. (2005). Pursuing happiness: The architecture of sustainable change. Review of General Psychology, 9(2), 111-131. doi: 10.1037/10892680.9.2.111

Mallett, R. K., Wilson, T. D., \& Gilbert, D. T. (2008). Expect the unexpected: Failure to anticipate similarities leads to an intergroup forecasting error. Journal of Personality and Social Psychology, 94(2), 265-277. doi: 10.1037/0022-3514.94.2.94.2.265

Martin, C. L., \& Ruble, D. N. (2004). Children's search for gender cues: Cognitive perspectives 


\section{HELPING TO PROMOTE GENDER EQUALITY}

on gender development. Current Directions in Psychological Science, 13, 67-70.

McGuire, A. M. (1994). Helping behaviors in the natural environment: Dimensions and correlates of helping. Personality and Social Psychology Bulletin, 20(1), 45-56.

McIntyre, K., Paolini, S., \& Hewstone, M. (2016). Changing people's views of outgroups through individual-to-group generalisation: Meta-analytic reviews and theoretical considerations. European Review of Social Psychology, 27(1), 63-115.

Miller, D. T. (1999). The norm of self-interest. American Psychologist, 54, 1053-1060.

Miller, D. T., \& McFarland, C. (1987). Pluralistic ignorance: When similarity is interpreted as dissimilarity. Journal of Personality and Social Psychology, 53(2), 298-305. doi: $10.1037 / 0022-3514.53 .2 .298$

Morelli, S. A., Lee, I. A., Arnn, M. E., \& Zaki, J. (2015). Emotional and instrumental support provision interact to predict well-being. Emotion, 15(4), 484.

Morison, L. A., Cozzolino, P. J., \& Orbell, S. (2010). Temporal perspective and parental intention to accept the human papillomavirus vaccination for their daughter. British Journal of Health Psychology, 15(15), 151-165.

Moss-Racusin, C. A. (2014). Male backlash: Penalties for men who violate gender stereotypes. In Gender in organizations. Edward Elgar Publishing.

Moss-Racusin, C. A., Phelan, J. E., \& Rudman, L. A. (2010). When men break the gender rules: Status incongruity and backlash against modest men. Psychology of Men \& Masculinity, 11(2), 140-151. doi: 10.1037/a0018093

Munsch, C. L., Ridgeway, C. L., \& Williams, J. C. (2014). Pluralistic ignorance and the 


\section{HELPING TO PROMOTE GENDER EQUALITY}

flexibility bias: Understanding and mitigating flextime and flexplace bias at work. Work and Occupations, 41(1), 40-62. doi: 10.1177/0730888413515894

Munsch, C. L., Weaver, J. R., Bosson, J. K., \& O’Connor, L. T. (2018). Everybody but me: Pluralistic ignorance and the masculinity contest. Journal of Social Issues, 74(3), 551-578. doi: $10.1111 /$ josi.12282

Nadler, A., \& Fisher, J. D. (1986). The role of threat to self-esteem and perceived control in recipient reaction to help: Theory development and empirical validation. In Advances in Experimental Social Psychology, 19, 81-122.

Nadler, A., \& Halabi, S. (2015). Helping relations and inequality between individuals and groups. In M. Mikulincer, P. R. Shaver, J. F. Dovidio, \& J. A. Simpson (Eds.), APA handbooks in psychology®. APA Handbook of Personality and Social Psychology, Vol. 2. Group processes (p. 371-393). American Psychological Association. https://doi.org/10.1037/14342-014

Nelson, S. K., Layous, K., Cole, S. W., \& Lyubomirsky, S. (2016). Do unto others or treat yourself? The effects of prosocial and self-focused behavior on psychological flourishing. Emotion, 16(6), 850-861. doi: 10.1037/emo0000178.supp

Newark, D. A., Bohns, V. K., \& Flynn, F. J. (2017). A helping hand is hard at work: Helpseekers' underestimation of helpers' effort. Organizational Behavior and Human Decision Processes, 139, 18-29.

Nolen-Hoeksema, S. \& Aldao, A. (2011). Gender and age differences in emotion regulation 


\section{HELPING TO PROMOTE GENDER EQUALITY}

strategies and their relationship to depressive symptoms. Personality and Individual Differences, 51(6), 704-708.

Orbell, S. (1996). Informal care in social context: A social psychological analysis of participation, impact and intervention in care of the elderly. Psychology and Health, 11(1), 155-178. doi: 10.1080/08870449608401980

Orbell, S., \& Hagger, M. (2006). Temporal framing and the decision to take part in type 2 diabetes screening: Effects of individual differences in consideration of future consequences on persuasion. Health Psychology, 25(4), 537-548. doi: 10.1037/0278-6133.25.4.537

Orbell, S., Lidierth, P., Henderson, C.J., Geeraert, N., Uller, C., Uskul, A.K., Kyriakaki, M. (2009). Social cognitive beliefs, alcohol and tobacco use: A prospective community study of change following a ban on smoking in public places. Health Psychology, 28, 753-761. https://doi.org/10.1037/a0016943

Orbell, S. \& Verplanken, B. (2010). The automatic component of habit in health behavior: Habit as cue-contingent automaticity. Health Psychology, 29, 374-

383. https://doi.org/10.1037/a0019596

Park, B., Smith, J. A., \& Correll, J. (2008). “Having it all” or “doing it all?” Perceived trait attributes and behavioral obligations as a function of workload, parenthood, and gender. European Journal of Social Psychology, 38, 1156-1164. doi:10.1002/ ejsp.535

Parkner, K. (2015, October 1). Women more than men adjust their careers for family life. Pew Research Center: Fact Tank News in the Numbers. https://www.pewresearch.org/facttank/2015/10/01/women-more-than-men-adjust-their-careers-for-family-life/ 


\section{HELPING TO PROMOTE GENDER EQUALITY}

Pearce, P. L., \& Amato, P. R. (1980). A taxonomy of helping: A multidimensional scaling analysis. Social Psychology Quarterly, 43(4), 363-371.

Penner., L. A., Dovidio., J. F., Piliavin., J. A., \& Schroeder., D. A. (2005). Prosocial behavior: Multilevel perspectives. Annual Review of Psychology, 56, 14.1-14.28. doi: 10.1146/annurev.psych.56.091103.070141

Pew Research Center. (2015, November 4). Raising kids and running a household: How working parents share the load. https://www.pewsocialtrends.org/2015/11/04/raising-kids-andrunning-a-household-how-working-parents-share-the-load/

Piliavin, J. A., Dovidio, J. F., Gaertner, S. L., \& Clark, R. D. I. (1981). Emergency intervention. New York: Academic Press.

Piliavin, J. A., \& Siegl, E. (2007). Health benefits of volunteering in the Wisconsin longitudinal study. Journal of Health and Social Behavior, 48, 450-464. doi:

\section{$10.1177 / 002214650704800408$}

Prentice, D. A., \& Carranza, E. (2002). What women and men should be, shouldn't be, are allowed to be, and don't have to be: The contents of prescriptive gender stereotypes. Psychology of Women Quarterly, 26(4), 269-281. doi: 10.1111/1471-6402.t01-1-00066

Prentice, D. A., \& Miller, D. T. (1996). Pluralistic ignorance and the perpetuation of social norms by unwitting actors. Advances in Experimental Social Psychology, 28, 161-209. doi: $10.1016 / \mathrm{S} 0065-2601(08) 60238-5$

Rankin, L. E., \& Eagly, A. H. (2008). Is his heroism hailed and hers hidden? Women, men and the social construction of heroism. Psychology of Women Quarterly, 32, 414-422. 


\section{HELPING TO PROMOTE GENDER EQUALITY}

Rapaport, P., \& Orbell, S. (2000). Augmenting the theory of planned behaviour: Motivation to provide practical assistance and emotional support to parents. Psychology and Health, 15(3), 309-324. doi: 10.1080/08870440008401995

Ridgeway, C. L., \& Correll, S. J. (2004). Unpacking the gender system. Gender \& Society, 18(4), 510-531. doi: 10.1177/0891243204265269

Richards, Z., \& Hewstone, M. (2001). Subtyping and subgrouping: Processes for the prevention and promotion of stereotype change. Personality and Social Psychology Review, 5(1), 52 73

Rose, A. J., \& Rudolph, K. D. (2006). A review of sex differences in peer relationship processes: Potential trade-offs for the emotional and behavioral development of girls and boys. Psychological Bulletin, 132(1), 98-131. doi: 10.1037/0033-2909.132.1.98.A

Rose, S., \& Frieze, I. H. (1993). Young singles' contemporary dating scripts. Sex Roles, 28(9/10), 499-509.

Ross, L. D., Amabile, T. M., \& Steinmetz, J. (1977). Social roles, social control, and biases in social percpetion. Journal of Personality and Social Psychology, 35, 485-494.

Roter, D. L., Hall, J. A., \& Aoki, Y. (2002). Physician gender effects in medical communication: A meta-analytic review. Journal of the American Medical Association, 288(6), 756-764.

Ruby, M. B., Dunn, E. W., Perrino, A., Gillis, R., \& Viel, S. (2011). The invisible benefits of exercise. Health Psychology, 30(1), 67-74. doi: 10.1037/a0021859

Rudman, L. A., \& Fairchild, K. (2004). Reactions to counterstereotypic behavior: The role of backlash in cultural stereotype maintenance. Journal of Personality and Social Psychology, 


\section{HELPING TO PROMOTE GENDER EQUALITY}

87(2), 157-176. doi: 10.1037/0022-3514.87.2.157

Rudman, L. A., \& Glick, P. (2001). Prescriptive gender stereotypes and backlash toward agentic women. Journal of Social Issues, 57(4), 743-762. doi: 10.1111/0022-4537.00239

Rudman, L. A., \& Mescher, K. (2013). Penalizing men who request a family leave: Is flexibility stigma a femininity stigma? Journal of Social Issues, 69(2), 322-340. doi: 10.1111/josi. 12017

Rudman, L. A., Moss-Racusin, C. A., Phelan, J. A., \& Nauts, S. (2012). Status incongruity and backlash effects: Defending the gender hierarchy motivates prejudice against female leaders. Journal of Experimental Social Psychology, 48, 165-179. doi: 10.1016/j.jesp.2011.10.008

Rudman, L. A., \& Phelan, J. E. (2008). Backlash effects for disconfirming gender stereotypes in organizations. Research in Organizational Behavior, 28, 61-79. doi: 10.1016/j.riob.2008.04.003

Sanchez, D. T., Fetterolf, J. C., \& Rudman, L. A. (2012). Eroticizing inequality in the United States: The consequences and determinants of traditional gender role adherence in intimate relationships. Journal of Sex Research, 49(2), 168-183. doi:

$10.1080 / 00224499.2011 .653699$

Sandberg, T., \& Conner, M. (2008). Anticipated regret as an additional predictor in the theory of planned behaviour: A meta-analysis. British Journal of Social Psychology, 47, 589-606. doi: $10.1348 / 014466607 X 258704$

Sandstrom, G. M., Schmader, T., Croft, A., \& Kwok, N. (2019). A social identity threat 


\section{HELPING TO PROMOTE GENDER EQUALITY}

perspective on being the target of generosity from a higher status other. Journal of Experimental Social Psychology, 82, 98-114.

Savitsky, K., Epley, N., \& Gilovich, T. (2001). Do others judge us as harshly as we think? Overestimating the impact of our failures, shortcomings, and mishaps. Journal of Personality and Social Psychology, 81(1), 44-56. doi: 10.1037/0022-3514.81.1.44

Schiappa, E., Gregg, P. B., \& Hewes, D. E. (2006). Can one TV show make a difference? A Will \& Grace and the parasocial contact hypothesis. Journal of Homosexuality, 51(4), 15-37.

Schmader, T., Major, B., Eccleston, C. P., \& McCoy, S. K. (2001). Devaluing domains in response to threatening intergroup comparisons: Perceived legitimacy and the status value asymmetry. Journal of Personality and Social Psychology, 80(5), 782796. https://doi.org/10.1037/0022-3514.80.5.782

Schonert-Reichl, K. A., Oberle, E., Lawlor, M. S., Abbott, D., Thomson, K., Oberlander, T. F., \& Diamond, A. (2015). Enhancing cognitive and social-emotional development through a simple-to-administer mindfulness-based school program for elementary school children: A randomized controlled trial. Developmental Psychology, 51(1), 52-66. doi: 10.1037/a0038454.Enhancing

Schwarz, N., Bless, H., Strack, F., Klumpp, G., Rittenauer-Schatka, H., \& Simons, A. (1991). Ease of retrieval as information: Another look at the availability heuristic. Journal of Personality and Social psychology, 61(2), 195.

Sheeran, P., \& Orbell, S. (1999). Implementation intentions and repeated behaviour: Augmenting the predictive validity of the theory of planned behaviour. European Journal of Social Psychology, 29, 349-369. 


\section{HELPING TO PROMOTE GENDER EQUALITY}

Sheldon, K. M., Gunz, A., Nichols, C. P., \& Ferguson, Y. (2010). Extrinsic value orientation and affective forecasting: Overestimating the rewards, underestimating the costs. Journal of Personality, 78(1), 149-178. doi: 10.1111/j.1467-6494.2009.00612.x

Shelton, J. N., \& Richeson, J. A. (2005). Intergroup contact and pluralistic ignorance. Journal of Personality and Social Psychology, 88(1), 91-107. doi: 10.1037/0022-3514.88.1.91

Shotland, R. L., \& Huston, T. L. (1979). Emergencies: What are they and do they influence bystanders to intervene? Journal of Personality and Social Psychology, 37(10), 1822-1834. doi: $10.1037 / 0022-3514.37 .10 .1822$

Simpson, P. A. \& Stroh, L. K. (2004). Gender differences: Emotional expression and feelings of personal inauthenticity. Journal of Applied Psychology, 89(4), 715-721.

Small, D., \& Loewenstein, G. (2003). Helping a victim or helping the victim: Altruism and identifiability. Journal of Risk and Uncertainty, 26(1), 5-16. doi: 10.1023/A

Smith, K. D., Keating, J. P., \& Stotland, E. (1989). Altruism reconsidered: The effect of denying feedback on a victim's status to empathic witnesses. Journal of Personality and Social Psychology, 57(4), 641-650. doi: 10.1037/0022-3514.57.4.641

Sprecher, S., Fehr, B., \& Zimmerman, C. (2007). Expectation for mood enhancement as a result of helping: The effects of gender and compassionate love. Sex Roles, 56(7), 543-549. doi: $10.1007 / \mathrm{s} 11199-007-9192-6$

Stout, J. G., Dasgupta, N., Hunsinger, M., \& McManus, M. A. (2011). STEMing the tide: Using ingroup experts to inoculate women's self-concept in science, technology, engineering, and mathematics (STEM). Journal of Personality and Social Psychology, 100(2), 255-270. doi: 


\section{HELPING TO PROMOTE GENDER EQUALITY}

\section{$10.1037 / \mathrm{a} 0021385$}

Stutzer, A., Goette, L., \& Zehnder, M. (2011). Active decisions and prosocial behaviour: a field experiment on blood donation. The Economic Journal, 121(556), F476-F493.

Taynor, J., \& Deaux, K. (1973). When women are more deserving than men: Equity, attribution, and perceived sex differences. Journal of Personality and Social Psychology, 28(3), 360367. doi: $10.1037 / \mathrm{h} 0035118$

Twenge, J. M. (1997). Changes in masculine and feminine traits over time: A meta-analysis. Sex Roles, 36(5-6), 305-325. doi: 10.1007/BF02766650

Van Grootel, S., Van Laar, C., Meeussen, L., Schmader, T., \& Sczesny, S. (2018). Uncovering pluralistic ignorance to change men's communal self-descriptions, attitudes, and behavioral intentions. Frontiers in Psychology, 9, 1344.

Van Tongeren, D. R., Green, J. D., Davis, D. E., Hook, J. N., \& Hulsey, T. L. (2016). Prosociality enhances meaning in life. Journal of Positive Psychology, 11(3), 225-236. doi: $10.1080 / 17439760.2015 .1048814$

Vandello, J. A., \& Bosson, J. K. (2013). Hard won and easily lost: A review and synthesis of theory and research on precarious manhood. Psychology of Men and Masculinity, 14(2), 101-113. doi: 10.1037/a0029826

Vandello, J. A., Bosson, J. K., Cohen, D., Burnaford, R. M., \& Weaver, J. R. (2008). Precarious manhood. Journal of Personality and Social Psychology, 95(6), 1325-1339. doi: $10.1037 / \mathrm{a} 0012453$

Verhofstadt, L. L., Buysse, A., \& Ickes, W. (2007). Social support in couples: An examination of 


\section{HELPING TO PROMOTE GENDER EQUALITY}

gender differences using self-report and observational methods. Sex Roles, 57(3-4), 267282.

Verplanken, B., Roy, D., Whitmarsh, L. (2018). Cracks in the wall: Habit discontinuities as vehicles for behaviour change. In B. Verplanken (Ed.) The Psychology of Habit. Springer: Switzerland (pp. 189-205. Doi: 10.1007/978-3-319-97529-0_11

Verplanken, B., Walker, I., Davis, A. \& Juraskek, M. (2008). Context change and travel mode choice: Combining the habit discontinuity and self-activation hypothesis. Journal of Environmental Psychology, 28, 121-127. Doi: 10.1016/j.envp.2007.10.005.

Verplanken, B. \& Wood, W. (2006). Interventions to break and create consumer habits. Journal of Public Policy and Marketing, 25, 90-103. Doi: 10.1509/jppm.25.1.90.

Ventimiglia, J. C. (1982). Sex roles and chivalry: Some conditions of gratitude to altruism. Sex Roles, 8(11), 1107-1122. doi: 10.1007/BF00290967

Willer, R. (2009). Groups reward individual sacrifice: The status solution to the collective action problem. American Sociological Review, 74, 23-43. doi: 10.1177/000312240907400102

Willer, R., Feinberg, M., Irwin, K., Schultz, M., \& Simpson, B. (2010). The trouble with invisible men: How reputational concerns motivate generosity. In S. Hitlin \& S. Vaisey (Eds.), Handbook of the sociology of morality (pp. 315-330). New York, NY: Springer. doi: 10.1007/978-1-4419-6896-8_17

Williams, M. J., \& Tiedens, L. Z. (2016). The subtle suspension of backlash: A meta-analysis of penalties for women's implicit and explicit dominance behavior. Psychological Bulletin, 142(2), 165. 


\section{HELPING TO PROMOTE GENDER EQUALITY}

Wilson, T. D., \& Gilbert, D. T. (2003). Affective forecasting. In P. Zanna, Mark \& M. A. Olson (Eds.), Advances in experimental social psychology (Vol. 35, pp. 345-411). Amsterdam: Academic Press.

Wilson, T. D., Wheatley, T., Meyers, J. M., Gilbert, D. T., \& Axsom, D. (2000). Focalism: A source of durability bias in affective forecasting. Journal of Personality and Social Psychology, 78(5), 821-836. doi: 10.1037/0022-3514.78.5.821

Wood, W., \& Eagly, A. H. (2010). Gender. In S. T. Fiske, T. Gilbert, \& G. Lindzey (Eds.), Handbook of social psychology (5th ed., pp. 629-667). New York, NY: Wiley.

Wood, W., \& Eagly, A. H. (2012). Biosocial construction of sex differences and similarities in behavior. In M. Olson, James \& P. Zanna, Mark (Eds.), Advances in experimental social psychology (1st ed., Vol. 46, pp. 55-123). Burlington: Academic Press. doi: 10.1016/B978$0-12-394281-4.00002-7$

Yeager, D. S., Walton, G. M., Brady, S. T., Akcinar, E. N., Paunesku, D., K. L., ... Dweck, C. S. (2016). Teaching a lay theory before college narrows achievement gaps at scale. Proceedings of the National Academy of Sciences, 113(24), 3341-3348. doi: 10.1073/pnas. 1524360113

Yeager, D. S., \& Dweck, C. S. (2012). Mindsets that promote resilience: When students believe that personal characteristics can be developed. Educational Psychologist, 47(4), 302-314. doi: 10.1080/00461520.2012.722805

Yoder, J. D., Hogue, M., Newman, R., Metz, L., \& LaVigne, T. (2002). Exploring moderators of gender differences: Contextual differences in door-holding behavior. Journal of Applied Social Psychology, 32(8), 1682-1686. doi: 10.1111/j.1559-1816.2002.tb02769.x 


\section{HELPING TO PROMOTE GENDER EQUALITY}

Zhou, B., Heather, D., Cesare, A. D., \& Ryder, A. G. (2017). Ask and you might receive: The actor-partner interdependence model approach to estimating cultural and gender variations in social support. European Journal of Social Psychology, 47(4), 412-428. 
Figure 1. The Gender Roles Inhibiting Prosociality (GRIP) Model: A theoretical framework integrating Social Role Theory (Eagly \& Wood, 2012) with the Theory of Planned Behavior (Ajzen, 1999) to predict engagement in gender-consistent helping.

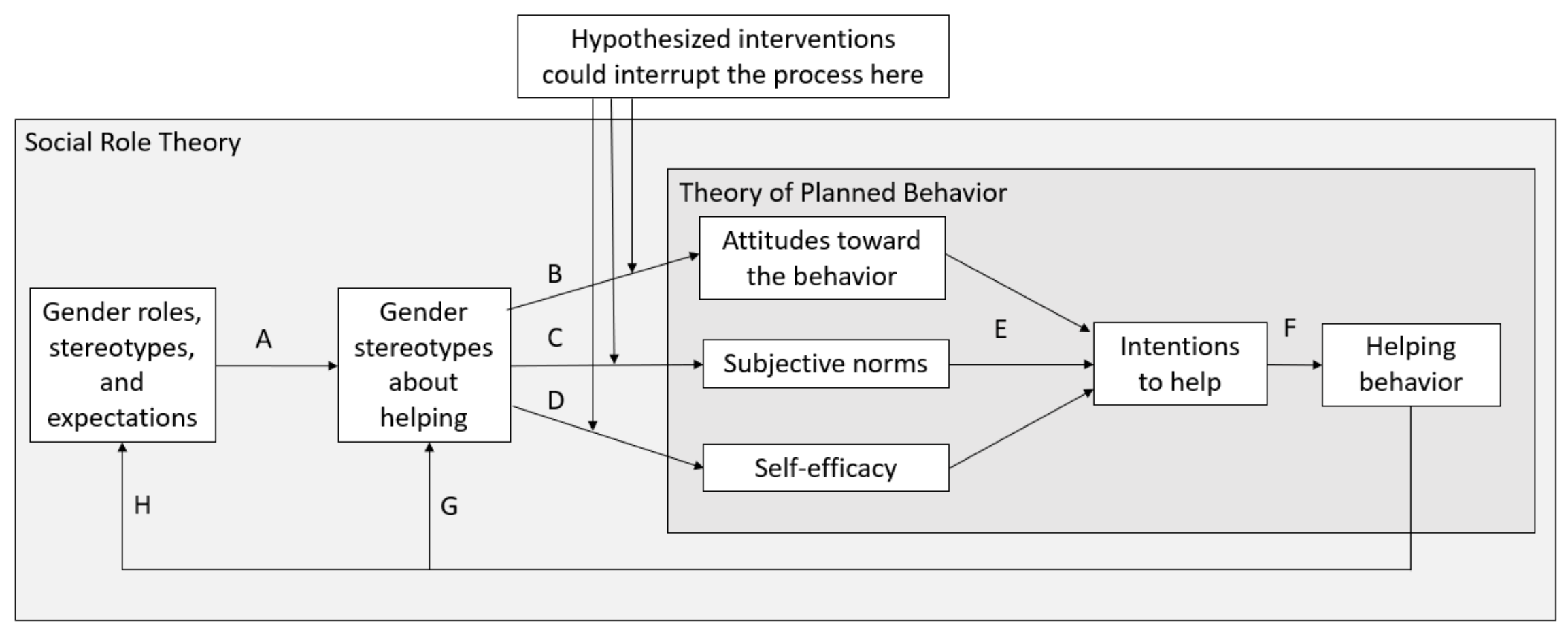


Table 1. Hypothesized interventions targeting each proximal factor in the GRIP model to increase gender-inconsistent helping.

GRIP

factor

factor Intervention

\begin{tabular}{|c|c|c|c|}
\hline \multirow{2}{*}{$\begin{array}{l}\text { Attitudes } \\
\text { toward } \\
\text { the } \\
\text { behavior }\end{array}$} & 1 & $\begin{array}{l}\text { Encourage people to think more broadly about } \\
\text { the benefits of helping and the regret } \\
\text { associated with NOT helping. }\end{array}$ & $\begin{array}{l}\text { Challenges affective forecasting errors related to } \\
\text { focalism by shifting people's attention away from } \\
\text { potential negative outcomes and toward potential } \\
\text { positive outcomes. }\end{array}$ \\
\hline & 2 & $\begin{array}{l}\text { Shift focus from away self and toward the } \\
\text { helping recipient. }\end{array}$ & $\begin{array}{l}\text { Diminishes concerns about negative consequences for } \\
\text { the self and highlights the positive prosocial impact } \\
\text { experienced by the recipient. }\end{array}$ \\
\hline \multirow[b]{2}{*}{$\begin{array}{l}\text { Subjective } \\
\text { norms }\end{array}$} & 3 & $\begin{array}{l}\text { Inform helpers that perceivers are not paying } \\
\text { as much attention to them as they think. }\end{array}$ & Undermines the spotlight effect. \\
\hline & 4 & $\begin{array}{l}\text { Affirm positive perceptions of helping by } \\
\text { educating helpers about } \\
\text { a. The lack of backlash against gender- } \\
\text { inconsistent helpers. } \\
\text { b. Possible empathetic responses from } \\
\text { others. } \\
\text { c. Others' willingness to engage in } \\
\text { gender-inconsistent helping. }\end{array}$ & $\begin{array}{l}\text { Reminds people that helping is valued by others and } \\
\text { emphasizes the empathy others might feel toward their } \\
\text { situation. Exposes pluralistic ignorance and shifts } \\
\text { perceptions of descriptive norms by making it easier for } \\
\text { people to recall instances of gender-inconsistent } \\
\text { helping. }\end{array}$ \\
\hline \multirow{2}{*}{$\begin{array}{c}\text { Self- } \\
\text { efficacy }\end{array}$} & 5 & $\begin{array}{l}\text { Provide opportunities for people to carry out } \\
\text { repeated acts of gender-inconsistent helping. }\end{array}$ & $\begin{array}{l}\text { Reinforces perceived capability through self-perception } \\
\text { (i.e., inferring characteristics about themselves by } \\
\text { observing their behavior). }\end{array}$ \\
\hline & 6 & $\begin{array}{l}\text { Teach people (children and adults) prosocial } \\
\text { skills via workshops, including processes to } \\
\text { trigger prosocial action with implementation } \\
\text { intentions (e.g., "when...then..." statements). }\end{array}$ & $\begin{array}{l}\text { Enhances ability to develop new skills, effort, } \\
\text { performance, and task engagement in a safe and } \\
\text { controlled environment. }\end{array}$ \\
\hline
\end{tabular}

\section{Rationale}

Strategy

.

